Research Article

\title{
Isogeometric Analysis for Active Control of Piezoelectric Functionally Graded Plates in Thermal Environment
}

\author{
Tao Liu $\mathbb{D}^{1,2,3}$ Yafen Jiang $\mathbb{D},{ }^{4}$ Shujun Li $\mathbb{D},{ }^{1}$ Qingyun Liu $\mathbb{D},{ }^{1,2}$ and Chao Wang $\mathbb{D}^{2}$ \\ ${ }^{1}$ Anhui Province Key Laboratory of Special Heavy Load Robot, Ma'anshan, 243032, China \\ ${ }^{2}$ Department of Mechanical Engineering, Anhui University of Technology, Ma'anshan, 243002, China \\ ${ }^{3}$ Department of Mechatronic Engineering and Automation, Shanghai University, Shanghai 200072, China \\ ${ }^{4}$ Department of Innovative Education, Anhui University of Technology, Ma'anshan, 243002, China \\ Correspondence should be addressed to Qingyun Liu; lqyahjx@ahut.edu.cn
}

Received 20 January 2021; Revised 18 March 2021; Accepted 26 March 2021; Published 15 May 2021

Academic Editor: Fabio Botta

Copyright $\odot 2021$ Tao Liu et al. This is an open access article distributed under the Creative Commons Attribution License, which permits unrestricted use, distribution, and reproduction in any medium, provided the original work is properly cited.

\begin{abstract}
An isogeometric analysis (IGA) method is proposed for investigating the active shape and vibration control of functionally graded plates (FGPs) with surface-bonded piezoelectric materials in a thermal environment. A simple first-order shear deformation theory (S-FSDT) with four variables is used to describe the displacement field of the plates. To ensure the investigation of smart piezoelectric structure in the thermal environment closer to the actual situation, a modified piezoelectric constitutive equation with consideration of the temperature effect of dielectric and piezoelectric strain coefficients is implemented to replace the traditional linear piezoelectric constitutive equation. Meanwhile, the neutral surface is adopted to avoid the stretching-bending coupling. The accuracy and effectiveness of the proposed S-FSDT-based IGA method are verified by comparing with several existing numerical examples. Then, the static bending and open-loop control of the plates under mechanical and thermal loads are further studied. Finally, the active control including static bending control and vibration control of piezoelectric functionally graded plates (PFGPs) is also investigated by using a displacement-velocity feedback control law.
\end{abstract}

\section{Introduction}

Smart piezoelectric structures are commonly used for active control in the fields of aerospace engineering [1]. As a type of smart structures, piezoelectric functionally graded plates (PFGPs) refer to using the functionally graded plates (FGPs) [2] as the substrate and using the piezoelectric materials as sensors or actuators. In the last few decades, many scholars have studied the active control of FGPs with surface-bonded piezoelectric layers. For instance, $\mathrm{He}$ et al. [3] used the finite element method (FEM) to study the active vibration control of PFGPs and the voltage response of the actuators and sensors. Nguyen-Quang et al. $[4,5]$ analyzed the vibration control of FGPs and functionally graded carbon nanotube reinforced composite (FG-CNTRC) plates. To avoid the reduction in calculation accuracy caused by element distortion [6], in FEM, Selim et al. [7] used the element-free method to research the active vibration control of functionally graded multilayer graphene nanoplatelets reinforced composite plates.

Indeed, the functional graded materials (FGMs) $[8,9]$ are often used in the thermal environment. Hence, the investigation of mechanical behavior of PFGPs in the thermal environment is conducive to improving the accuracy of structural analysis and design. Yang et al. [10,11] estimated the nonlinear free vibration and static bending analysis of PFGPs in the thermal environment. Liew et al. [12] analyzed the static shape and vibration control of PFGPs. Dai et al. [13] researched the vibration control of PFGPs with the element-free method. However, they did not consider the temperature field of piezoelectric layers. An exact approach for nonlinear vibration and dynamic responses of PFGPs in the thermal environment was developed by Huang and Shen [14] and Xia and Shen [15]. Similarly, Fakhari et al. [16, 17] developed a nonlinear investigation for the transient response and vibration control of PFGPs. Phung-Van et al. 
[18] employed isogeometric analysis (IGA) [19] to investigate the nonlinear dynamic response of PFGPs. Although the temperature field of piezoelectric materials was considered in [14-18], the effect of temperature on the properties of piezoelectric materials was not considered.

Different from these references, Shen [20] assumed that the material properties of PZT-5A vary linearly with temperature to research the thermal bending of PFGPs, but the effect of temperature on the dielectric parameter and piezoelectric strain parameter was not considered. The authors in [21] prove that the dielectric and piezoelectric strain parameters are sensitive to temperature. Undoubtedly, it is helpful to make the analysis closer to the actual situation if the influence of temperature on dielectric and piezoelectric strain parameters can be considered in the analysis of smart piezoelectric structure in the thermal environment.

For the numerical method of smart piezoelectric structures and nonhomogeneous composites, although FEM $[22,23]$ and meshless methods [24] have been proved to be successful and effective, some scholars are still trying to find superior numerical methods for research. Owing to the outstanding features of the exact geometrical modeling, high-order continuity, and simple meshing [25], IGA has been used in a variety of engineering applications [26-31]. Besides, the mathematical model of smart piezoelectric structures is complicated due to the existence of the electric field. Thus, an accurate method with low calculation cost is distinctly important. Obviously, the calculation efficiency and accuracy are directly affected by the number of variables in plate theories. In plate theories, classical plate theory (CPT) [3] has only three variables, whereas it is only appropriate for thin plates. There are five variables in firstorder shear deformation theory (FSDT) [32], but the shearlocking effect will occur in the analysis of thin plates. Higherorder shear deformation theories (HSDTs) [33] and some other theories [34] have five or more variables, which make the discretization process more complicated. It is worth noting that, by adopting a simple first-order shear deformation theory (S-FSDT) with only four variables, Yu et al. [35] used the IGA method to investigate the free vibration and nonlinear static bending responses of FGPs. The results indicated that the S-FSDT-based IGA method is both applicable for thin and thick plates and naturally free from shear-locking.

This paper thus aims to develop an investigation for the active shape and vibration control of PFGPs in the thermal environment based on the S-FSDT and isogeometric analysis method. The neutral surface is introduced into the S-FSDT for avoiding the stretching-bending coupling. Additionally, to make the investigation of smart piezoelectric structure in the thermal environment close to the actual situation, a modified piezoelectric constitutive equation considering the temperature effect of dielectric and piezoelectric stress parameters is applied to substitute the traditional linear piezoelectric constitutive equation in the derivation of isogeometric finite element equation of PFGPs.

\section{PFGPs in Thermal Environment}

The sizes of the plate depicted in Figure 1 are $a \times b \times h_{t}$ (length $\times$ width $\times$ thickness). $h_{t}=h_{f}+2 h_{p}$, where $h_{f}$ and $h_{p}$ are the thickness of FGP and piezoelectric layers. $z_{0}$ is the distance between the midsurface and neutral surface. $T_{u}$ and $T_{c}$ are the temperature of the top surface of PFGP and FGP. $T_{l}$ and $T_{m}$ are the temperature of the bottom surface of PFGP and FGP.

2.1. Material Properties. The material properties of the FGP are defined as

$$
P(z, T)=\left(P_{c}-P_{m}\right)\left(\frac{1}{2}+\frac{z}{h_{f}}\right)^{n}+P_{m},
$$

where $z$ is the thickness coordinate and $z \in\left[h_{f} / 2-h_{f} / 2\right] . n$ is the gradient index. $T$ is the temperature. $P_{c}$ and $P_{m}$ represent the material properties of ceramic and metal.

In the thermal environment, $P_{c}$ and $P_{m}$ can be obtained as follows [16]:

$$
P_{c / m}=P_{0}\left(P_{-1} T^{-1}+1+P_{1} T+P_{2} T^{2}+P_{3} T^{3}\right),
$$

where $P_{-1}, P_{0}, P_{1}, P_{2}$, and $P_{3}$ are the material coefficients related to the temperature and are unique to the constituent materials.

2.2. Temperature Distribution. The temperature along the thickness can be acquired by calculating the steady-state heat transfer equation [36]:

$$
-\frac{\mathrm{d}}{\mathrm{d} z}\left(k(z) \frac{\mathrm{d} T(z)}{\mathrm{d} z}\right)=0,
$$

where $k$ is the thermal conductivity.

Combined with the thermal boundary conditions and continuity conditions [37], the temperature distribution can be given by

$$
T(z)=T_{l}+\frac{T_{u}-T_{l}}{\int_{-h_{t} / 2}^{h_{t} / 2}(1 / k(z)) \mathrm{d} z} \int_{-h_{t} / 2}^{z} \frac{1}{k(z)} \mathrm{d} z .
$$

2.3. Constitutive Equation. By introducing the influence of temperature on dielectric and piezoelectric stress parameters into the traditional linear piezoelectric constitutive equation [38], the modified piezoelectric constitutive equation is defined as

$$
\begin{aligned}
\boldsymbol{\sigma} & =\mathbf{Q} \widetilde{\boldsymbol{\varepsilon}}-\widehat{\mathbf{e}}^{\mathrm{T}} \mathbf{E}-\mathbf{Q} \boldsymbol{\alpha} \Delta T, \\
\mathbf{D} & =\widehat{\mathbf{e}} \widetilde{\boldsymbol{\varepsilon}}+\widehat{\mathbf{g}} \mathbf{E}+\mathbf{P} \Delta \mathbf{T}, \\
\mathbf{S} & =\boldsymbol{\alpha}^{\mathrm{T}} \mathbf{Q}^{\mathrm{T}} \widetilde{\boldsymbol{\varepsilon}}+\mathbf{P}^{\mathrm{T}} \mathbf{E}+\bar{C} \Delta \mathbf{T},
\end{aligned}
$$

where $\boldsymbol{\sigma}$ and $\widetilde{\boldsymbol{\varepsilon}}$ are stress and strain. $\mathbf{D}$ is the electric displacement vector. $\mathbf{S}$ and $\bar{C}$ are entropy and specific heat. $\mathbf{E}$ is 


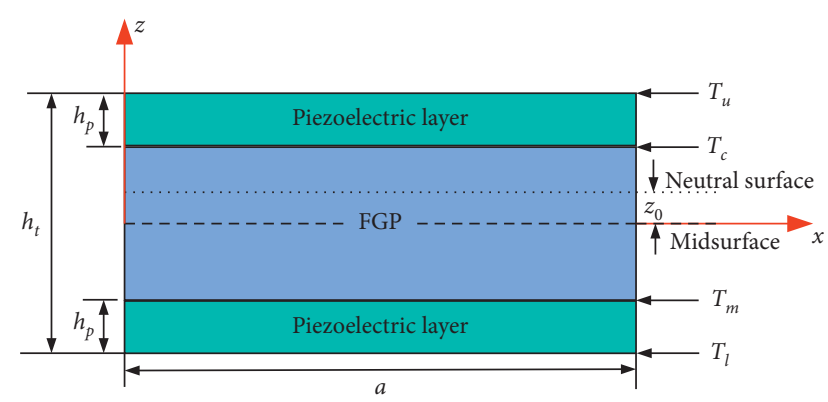

FIGURE 1: Piezoelectric functionally graded plate.

the electric field vector, and $\mathbf{Q}$ is the elastic constant matrix. $\Delta T=T(z)-T_{0}$, in which $T_{0}$ is the reference temperature. $\alpha$ and $\mathbf{P}$ are thermal expansion coefficient and pyroelectric vectors. $\widehat{e}$ and $\hat{g}$ are temperature-dependent piezoelectric stress parameter and dielectric parameter matrices. The specific forms of $\alpha, \mathbf{P}, \hat{e}$, and $\hat{g}$ are

$$
\begin{aligned}
& \boldsymbol{\alpha}=\left\{\begin{array}{lllll}
\alpha_{x} & \alpha_{y} & 0 & 0 & 0
\end{array}\right\}^{\mathrm{T}}, \\
& \mathbf{P}=\left\{\begin{array}{lll}
P_{1} & P_{2} & P_{3}
\end{array}\right\}^{\mathrm{T}}, \\
& \widehat{e}=\mathbf{e}+\widetilde{e} \Delta T, \\
& \widehat{g}=\mathbf{g}+\widetilde{g} \Delta T,
\end{aligned}
$$

with

$$
\begin{aligned}
\widehat{\mathbf{e}} & =\left[\begin{array}{ll}
\widehat{\mathbf{e}}_{m} & \widehat{\mathbf{e}}_{s}
\end{array}\right], \\
\widehat{\mathbf{e}}_{m} & =\left[\begin{array}{ccc}
0 & 0 & 0 \\
0 & 0 & 0 \\
\widehat{e}_{31} & \widehat{e}_{32} & 0
\end{array}\right], \\
\widehat{\mathbf{e}}_{s} & =\left[\begin{array}{cc}
0 & \widehat{e}_{24} \\
\widehat{e}_{15} & 0 \\
0 & 0
\end{array}\right], \\
\widehat{\mathbf{g}} & =\left[\begin{array}{ccc}
\widehat{g}_{11} & 0 & 0 \\
0 & \widehat{g}_{22} & 0 \\
0 & 0 & \widehat{g}_{33}
\end{array}\right],
\end{aligned}
$$

where $\mathbf{e}$ and $\mathbf{g}$ are piezoelectric stress and dielectric constant matrices at reference temperature. $\widetilde{\mathbf{e}}$ and $\widetilde{\mathbf{g}}$ are the coefficients that need to be confirmed through experiments.

2.4. Displacement Field and Strain. By introducing the neutral surface, the displacement field in S-FSDT [35] is given as

$$
\begin{aligned}
& u(x, y, z)=u_{0}(x, y)-\left(z-z_{0}\right) \frac{\partial w_{b}}{\partial x} \\
& v(x, y, z)=v_{0}(x, y)-\left(z-z_{0}\right) \frac{\partial w_{b}}{\partial y}, \\
& w(x, y, z)=w_{b}(x, y)+w_{s}(x, y),
\end{aligned}
$$

where $u_{0}$ and $v_{0}$ denote the displacements of neutral surface. $z_{0}$ is given by

$$
z_{0}=\frac{\int_{-h_{t} / 2}^{h_{t} / 2} z E(z) \mathrm{d} z}{\int_{-h_{t} / 2}^{h_{t} / 2} E(z) \mathrm{d} z} .
$$

It is seen that the transverse displacement $w_{0}(x, y)$ in FSDT $[39,40]$ is expressed by bending $\left(w_{b}\right)$ and shear $\left(w_{s}\right)$ terms; and the rotation variables are denoted by using the partial derivatives of the transverse bending components $\left(\beta_{x}=-\partial w_{b} / \partial x, \beta_{y}=-\partial w_{b} / \partial y\right)$ in S-FSDT. Through the above expressions, we can see that there are only four variables in S-FSDT.

The strain-displacement relation is

$$
\widetilde{\boldsymbol{\varepsilon}}=\left\{\begin{array}{c}
\boldsymbol{\varepsilon}_{m} \\
0
\end{array}\right\}+\left\{\begin{array}{c}
-\left(z-z_{0}\right) \boldsymbol{\varepsilon}_{b} \\
\boldsymbol{\gamma}
\end{array}\right\},
$$

where

$$
\begin{aligned}
& \boldsymbol{\varepsilon}_{m}=\left\{\begin{array}{lll}
u_{0, x} & v_{0, y} & u_{0, y}+v_{0, x}
\end{array}\right\}^{\mathrm{T}}, \\
& \boldsymbol{\varepsilon}_{b}=\left\{\frac{\partial^{2} w_{b}}{\partial x^{2}} \frac{\partial^{2} w_{b}}{\partial y^{2}} \frac{2 \partial^{2} w_{b}}{\partial x \partial y}\right\}^{\mathrm{T}}, \\
& \boldsymbol{\gamma}=\left\{\begin{array}{ll}
\gamma_{x z} & \gamma_{y z}
\end{array}\right\}^{\mathrm{T}}=\left\{\frac{\partial w_{s}}{\partial x} \frac{\partial w_{s}}{\partial y}\right\}^{\mathrm{T}} .
\end{aligned}
$$

The stress resultants of PFGPs can be calculated by

$$
\begin{aligned}
\mathbf{N}=\left\{\begin{array}{lll}
N_{x}^{T} & N_{y}^{T} & N_{x y}^{T}
\end{array}\right\}^{\mathrm{T}} & =\int_{-h_{t} / 2}^{h_{t} / 2}\left\{\begin{array}{lll}
\sigma_{x}^{T} & \sigma_{y}^{T} & \sigma_{x y}^{T}
\end{array}\right\}^{\mathrm{T}} \mathrm{d} z, \quad \text { (15a) } \\
\mathbf{M} & =\left\{\begin{array}{lll}
M_{x}^{T} & M_{y}^{T} & M_{x y}^{T}
\end{array}\right\}^{\mathrm{T}} \\
& =\int_{-h_{t} / 2}^{h_{t} / 2}\left\{\begin{array}{lll}
\sigma_{x}^{T} & \sigma_{y}^{T} & \sigma_{x y}^{T}
\end{array}\right\}^{\mathrm{T}}\left(z-z_{0}\right) \mathrm{d} z, \\
\overline{\mathbf{Q}} & =\left\{\begin{array}{ll}
\overline{\mathbf{Q}}_{x}^{T} & \overline{\mathbf{Q}}_{y}^{T}
\end{array}\right\}^{\mathrm{T}} \\
& =\int_{-h_{t} / 2}^{h_{t} / 2}\left\{\begin{array}{ll}
\sigma_{x z}^{T} & \sigma_{y z}^{T}
\end{array}\right\}^{\mathrm{T}} \mathrm{d} z,
\end{aligned}
$$

where $\mathbf{N}, \mathbf{M}$, and $\overline{\mathbf{Q}}$ denote in-plane forces, moments, and shear forces.

Substituting equation (5) into equations (15a)-(15c) yields 


$$
\left\{\begin{array}{c}
\mathbf{N} \\
\mathbf{M} \\
\overline{\mathbf{Q}}
\end{array}\right\}=\bar{c}\left\{\begin{array}{c}
\boldsymbol{\varepsilon}_{m} \\
\boldsymbol{\varepsilon}_{b} \\
\boldsymbol{\gamma}
\end{array}\right\}-\left\{\begin{array}{c}
\mathbf{N}^{p} \\
\mathbf{M}^{p} \\
0
\end{array}\right\}-\left\{\begin{array}{c}
\mathbf{N}^{\mathrm{th}} \\
\mathbf{M}^{\mathrm{th}} \\
0
\end{array}\right\}
$$

where

$$
\widehat{\mathbf{c}}=\left[\begin{array}{cc}
\mathbf{D}_{m b} & 0 \\
0 & \mathbf{C}_{s}
\end{array}\right]
$$

with

$$
\begin{aligned}
\mathbf{D}_{m b} & =\left[\begin{array}{ll}
\mathbf{A} & \mathbf{B} \\
\mathbf{B} & \mathbf{D}
\end{array}\right], \\
\mathbf{C}_{s} & =k_{s} \int_{-h t / 2}^{h t / 2} Q_{i j} \mathrm{~d} z, \quad i, j=4,5,
\end{aligned}
$$

$$
\begin{aligned}
\left(A_{i j}, B_{i j}, D_{i j}\right)= & \int_{-h t / 2}^{h t / 2} Q_{i j}\left(1,\left(z-z_{0}\right),\left(z-z_{0}\right)^{2}\right) \mathrm{d} z, \\
& i, j=1,2,6
\end{aligned}
$$

in which the shear correction factor $k_{s}=5 / 6$ and $B_{i j}=0$ [41].

The thermal and electric stress resultants can be calculated by

$$
\begin{aligned}
\left(\mathbf{N}^{p}, \mathbf{M}^{p}\right) & =\int_{\left(h_{f} / 2\right)}^{\left(h_{f} / 2\right)+h_{p}} \hat{e}_{m}^{T} \mathbf{E}\left(1, z-z_{0}\right) \mathrm{d} z+\int_{-\left(h_{f} / 2\right)-h_{p}}^{-\left(h_{f} / 2\right)} \hat{e}_{m}^{T} \mathbf{E}\left(1, z-z_{0}\right) \mathrm{d} z, \\
\left(\mathbf{N}^{\text {th }}, \mathbf{M}^{\text {th }}\right) & =\int_{\left(h_{f} / 2\right)}^{\left(h_{f} / 2\right)+h_{p}} \mathbf{Q}_{m} \boldsymbol{a}_{m} \Delta T\left(1, z-z_{0}\right) \mathrm{d} z+\int_{-\left(h_{f} / 2\right)}^{\left(h_{f} / 2\right)} \mathbf{Q}_{m} \boldsymbol{a}_{m} \Delta T\left(1, z-z_{0}\right) \mathrm{d} z+\int_{-\left(h_{f} / 2\right)-h_{p}}^{-\left(h_{f} / 2\right)} \mathbf{Q}_{m} \boldsymbol{a}_{m} \Delta T\left(1, z-z_{0}\right) \mathrm{d} z,
\end{aligned}
$$

with

$$
\begin{aligned}
& \mathbf{Q}_{m}=\left[\begin{array}{ccc}
Q_{11} & Q_{12} & 0 \\
Q_{21} & Q_{22} & 0 \\
0 & 0 & Q_{66}
\end{array}\right], \\
& \boldsymbol{\alpha}_{m}=\left\{\begin{array}{lll}
\alpha_{x} & \alpha_{y} & 0
\end{array}\right\}^{\mathrm{T}} .
\end{aligned}
$$

2.5. Weak Form of Governing Equation. The equations of equilibrium and electrostatics can be denoted as follows [12]:

$$
\begin{aligned}
\sigma_{i j, j}+f_{b i} & =\rho \ddot{u}, \\
D_{i, j} & =0,
\end{aligned}
$$

where $\sigma_{i j}$ and $f_{b i}$ are the components of the stress tensor and the body force. $D$ represents the component of the electric displacement vector. $\rho$ is the density.

By introducing the mechanical and electric boundary conditions $[12,30]$, the weak form of PFGPs can be obtained through Hamilton's principle which can be expressed as

$$
\delta \int_{t_{1}}^{t_{2}} L \mathrm{~d} t=0
$$

in which

$$
\begin{aligned}
L= & \frac{1}{2} \int_{\Omega}\left(\rho \dot{u}^{T} \dot{u}-\sigma^{T} \widetilde{\varepsilon}+\mathbf{D}^{T} \mathbf{E}\right) \mathrm{d} \Omega+\int_{\Gamma_{s}} \mathbf{u}^{T} f_{s} \mathrm{~d} \Gamma-\int_{\Gamma_{\phi}} \boldsymbol{\varphi \mathbf { q } _ { s }} \mathrm{d} \Gamma_{\phi} \\
& +\sum \mathbf{u}^{T} \mathbf{f}_{p},
\end{aligned}
$$

where $\mathbf{u}$ and $\dot{u}$ are the displacement and velocity. $\mathbf{f}_{p}$ and $\mathbf{f}_{s}$ represent mechanical point and surface loads, respectively. $\mathbf{q}_{s}$ is the surface charge. $\Gamma_{s}$ and $\Gamma_{\phi}$ denote boundaries of $\Omega$ corresponding to the external mechanical and the electrical loading surface, respectively.

2.6. Isogeometric Analysis. The NURBS basis function for the two-dimensional problems is expressed as follows [42]:

$$
N_{i, j}^{p, q}(\xi, \eta)=\frac{B_{i, p}(\xi) B_{j, q}(\eta) w_{i, j}}{\sum_{i=1}^{n} \sum_{j=1}^{m} B_{i, p}(\xi) B_{j, q}(\eta) w_{i, j}},
$$

where $B_{i, p}(\xi)$ and $B_{j, q}(\eta)$ denote the B-spline basis functions with orders $p$ and $q$ in $\xi$ and $\eta$ directions, respectively. $w_{i, j}$ is the weight.

The displacements of the plate can be approximated as

$$
\mathbf{u}(\xi, \eta)=\left[\begin{array}{llll}
u_{0} & v_{0} & w_{b} & w_{s}
\end{array}\right]^{T}=\sum_{I=1}^{m \times n} N_{I}(\xi, \eta) \mathbf{d}_{I},
$$

where $\mathbf{d}_{I}=\left[\begin{array}{llll}u_{0 I} & v_{0 I} & w_{b I} & w_{s I}\end{array}\right]^{T}$ represents the displacement vector of control point $I . N_{I}(\xi, \eta)$ denotes the NURBS basis function.

Substituting equation (25) into equations (14a)-(14c) yields

$$
\boldsymbol{\varepsilon}_{m}=\sum_{I=1}^{m \times n} B_{I}^{m} \mathbf{d}_{I}, \boldsymbol{\varepsilon}_{b}=\sum_{I=1}^{m \times n} \mathbf{B}_{I}^{b} \mathbf{d}_{I}, \boldsymbol{\gamma}=\sum_{I=1}^{m \times n} B_{I}^{s} d_{I},
$$

where 


$$
\begin{aligned}
& \mathbf{B}_{I}^{m}=\left[\begin{array}{cccc}
N_{I, x} & 0 & 0 & 0 \\
0 & N_{I, y} & 0 & 0 \\
N_{I, y} & N_{I, x} & 0 & 0
\end{array}\right], \\
& \mathbf{B}_{I}^{b}=\left[\begin{array}{llll}
0 & 0 & N_{I, x x} & 0 \\
0 & 0 & N_{I, y y} & 0 \\
0 & 0 & 2 N_{I, x y} & 0
\end{array}\right], \\
& \mathbf{B}_{I}^{s}=\left[\begin{array}{llll}
0 & 0 & 0 & N_{I, x} \\
0 & 0 & 0 & N_{I, y}
\end{array}\right] .
\end{aligned}
$$

Similarly, the electric potential of piezoelectric layers can be approximated as

$$
\varphi=\sum_{I=1}^{m \times n} \mathbf{N}_{I} \boldsymbol{\varphi}_{I} .
$$

The electric field is then given by

$$
\mathbf{E}=-\nabla \varphi=-\sum_{I=1}^{m \times n} \mathbf{B}_{\varphi I} \boldsymbol{\varphi}_{I} .
$$

The electric field in $x$ and $y$ directions is ignored; hence,

$$
\mathbf{B}_{\varphi I}=\left\{\begin{array}{lll}
0 & 0 & \frac{N_{I}}{h_{p}}
\end{array}\right\}^{\mathrm{T}} .
$$

Then, by substituting equations (5) and (26) and (25)-(29) into equation (25), the governing equations of PFGPs are expressed as

$$
\begin{aligned}
\mathbf{M}_{u u} \ddot{d}+\mathbf{K}_{u u} \mathbf{d}+\mathbf{K}_{u \varphi} \boldsymbol{\varphi} & =\mathbf{f}+\mathbf{f}_{\mathrm{th}}, \\
\mathbf{K}_{\varphi u} \mathbf{d}-\mathbf{K}_{\varphi \varphi} \boldsymbol{\varphi} & =\mathbf{f}_{\varphi}-\mathbf{f}_{\varphi \theta} .
\end{aligned}
$$

After simplification, equations (31a) and (31b) are rewritten as

$$
\begin{gathered}
\mathbf{M}_{u u} \ddot{d}+\overline{\mathbf{K}} \mathbf{d}=\mathbf{F}, \\
\overline{\mathbf{K}}=\mathbf{K}_{u u}+\mathbf{K}_{u \varphi} \mathbf{K}_{\varphi \varphi}^{-1} \mathbf{K}_{\varphi u}, \\
\mathbf{F}=\mathbf{f}+\mathbf{f}_{\mathrm{th}}+\mathbf{K}_{u \varphi} \mathbf{K}_{\varphi \varphi}^{-1} \mathbf{f}_{\varphi}-\mathbf{K}_{u \varphi} \mathbf{K}_{\varphi \varphi}^{-1} \mathbf{f}_{\varphi \theta} .
\end{gathered}
$$

The specific form of items in equation (32) is given as

$$
\begin{aligned}
\mathbf{M}_{u u} & =\int_{V} \bar{\Lambda}^{T} \mathbf{m} \bar{\Lambda} \mathrm{d} V, \\
\mathbf{K}_{u u} & =\int_{V} \mathbf{B}_{u}^{T} \widehat{c}_{\mathbf{B}_{u}} \mathrm{~d} V, \\
\mathbf{K}_{u \varphi} & =\int_{V} \mathbf{B}_{u}^{T} \widehat{e}^{T} \mathbf{B}_{\varphi} \mathrm{d} V, \\
\mathbf{K}_{\varphi \varphi} & =\int_{V} \mathbf{B}_{\varphi}^{T} \hat{g} \mathbf{B}_{\varphi} \mathrm{d} V, \\
\mathbf{K}_{\varphi u} & =\mathbf{K}_{u \varphi}^{T}, \\
\mathbf{f} & =\mathbf{R}^{T} \mathbf{f}_{p}+\int_{\Omega} \mathbf{R}^{T} \mathbf{f}_{s} \mathrm{~d} \Omega+\int_{V} \mathbf{R}^{T} \mathbf{f}_{b} \mathrm{~d} V, \\
\mathbf{f}_{\mathrm{th}} & =\int_{V}\left(\left(\mathbf{B}_{m}\right)^{T} \mathbf{N}^{\mathrm{th}}+\left(\mathbf{B}_{b}\right)^{T} \mathbf{M}^{\mathrm{th}}\right) \mathrm{d} V, \\
\mathbf{f}_{\varphi} & =\int_{\Omega} \mathbf{R}^{T} q_{E} \mathrm{~d} \Omega, \\
q_{E} & =\widehat{g}_{33} \frac{\bar{U}}{h_{p}}, \\
\mathbf{f}_{\varphi \theta} & =\int_{V} \mathbf{B}_{\varphi}^{T} \mathbf{P} \Delta T \mathrm{~d} V,
\end{aligned}
$$

with

$$
\begin{aligned}
& \mathbf{m}=\left[\begin{array}{ll}
I_{0} & I_{1} \\
I_{1} & I_{2}
\end{array}\right], \\
& \bar{\Lambda}=\left[\begin{array}{ll}
\Lambda_{1} & \Lambda_{2}
\end{array}\right]^{T}, \\
& \left(I_{0}, I_{1}, I_{2}\right)=\int_{-h_{t} / 2}^{h_{t} / 2} \rho(z)\left(1,\left(z-z_{0}\right),\left(z-z_{0}\right)^{2}\right) \mathrm{d} z, \\
& \Lambda_{1}=\left[\begin{array}{cccc}
N_{I} & 0 & 0 & 0 \\
0 & N_{I} & 0 & 0 \\
0 & 0 & N_{I} & N_{I}
\end{array}\right] \text {, } \\
& \boldsymbol{\Lambda}_{2}=\left[\begin{array}{cccc}
0 & 0 & N_{I, x} & 0 \\
0 & 0 & N_{I, y} & 0 \\
0 & 0 & 0 & 0
\end{array}\right] \text {. }
\end{aligned}
$$

\section{Closed-Loop Control}

The active control of smart piezoelectric structures mainly includes two types: one is the open-loop control, which uses the inverse piezoelectric effect of piezoelectric materials to 
change the shape of the structures by applying voltage; the other is the closed-loop control, that is, using piezoelectric materials as sensors to sense the state of the structures; then, the output voltage of sensors is amplified as the input voltage of the actuators to control the deformation or suppress the vibration of structures.

In this paper, the upper piezoelectric layer is applied as an actuator, whereas the lower piezoelectric layer is used as a sensor. In general, the external charge of the sensor is zero. Therefore, using the subscripts $a$ and $s$ to express the actuator and sensor, equation (31b) can be rewritten as

$$
\begin{aligned}
& \mathbf{K}_{\varphi u a} \mathbf{d}-\mathbf{K}_{\varphi \varphi a} \boldsymbol{\varphi}=\mathbf{f}_{\varphi a}-\mathbf{f}_{\varphi \theta a}, \\
& \mathbf{K}_{\varphi u s} \mathbf{d}-\mathbf{K}_{\varphi \varphi s} \boldsymbol{\varphi}=-\mathbf{f}_{\varphi \theta s} .
\end{aligned}
$$

The electric potential generated in the sensor is given by

$$
\boldsymbol{\varphi}_{s}=\mathbf{K}_{\varphi \varphi s}^{-1}\left(\mathbf{K}_{\varphi u s} \mathbf{d}+\mathbf{f}_{\varphi \theta s}\right) .
$$

According to the displacement-velocity feedback control law [43], $\varphi_{a}$ can be calculated by

$$
\boldsymbol{\varphi}_{a}=G_{d} \boldsymbol{\varphi}_{s}+G_{v} \dot{\varphi}_{s},
$$

where $G_{d}$ and $G_{v}$ represent the displacement and velocity feedback control gains.

Substituting equations (39) and (40) into equation (37) yields

$$
\begin{aligned}
\mathbf{f}_{\varphi a}= & \mathbf{K}_{u \varphi a} \mathbf{d}+\mathbf{f}_{\varphi \theta a}-G_{d} \mathbf{K}_{\varphi \varphi a} \mathbf{K}_{\varphi \varphi s}^{-1}\left(\mathbf{K}_{\varphi u s} \mathbf{d}+\mathbf{f}_{\varphi \theta s}\right) \\
& -\mathbf{G}_{v} \mathbf{K}_{\varphi \varphi a} \mathbf{K}_{\varphi \varphi s}^{-1}\left(\mathbf{K}_{\varphi u s} \dot{d}+\dot{f}_{\varphi \theta s}\right) .
\end{aligned}
$$

Substituting equation (41) into equation (32) and introducing the Rayleigh damping $\mathbf{C}_{s}$, the final form of governing equation is expressed as

$$
\begin{gathered}
\mathbf{M}_{u u} \ddot{\mathbf{d}}+\left(\mathbf{C}+\mathbf{C}_{s}\right) \dot{\mathbf{d}}+\bar{K}^{*} \mathbf{d}=\mathbf{F}^{*}, \\
\mathbf{C}=G_{v} \mathbf{K}_{u \varphi a} \mathbf{K}_{\varphi \varphi s}^{-1} \mathbf{K}_{\varphi u s}, \\
\bar{K}^{*}=\mathbf{K}_{u u}+\mathbf{K}_{u \varphi s} \mathbf{K}_{\varphi \varphi s}^{-1} \mathbf{K}_{\varphi u s}+G_{d} \mathbf{K}_{u \varphi a} \mathbf{K}_{\varphi \varphi s}^{-1} \mathbf{K}_{\varphi u s}, \\
\mathbf{F}^{*}=\mathbf{f}+\mathbf{f}_{\mathrm{th}}-G_{d} \mathbf{K}_{u \varphi a} \mathbf{K}_{\varphi \varphi s}^{-1} \mathbf{f}_{\varphi \theta s}-\mathbf{K}_{u \varphi s} \mathbf{K}_{\varphi \varphi s}^{-1} \mathbf{f}_{\varphi \theta s} \\
-G_{v} \mathbf{K}_{u \varphi q} \mathbf{K}_{\varphi \varphi s}^{-1} \dot{f}_{\varphi \theta s} .
\end{gathered}
$$

The Rayleigh damping $\mathbf{C}_{s}$ in equation (42) can be calculated by

$$
\mathbf{C}_{s}=\alpha_{R} \mathbf{M}_{u u}+\beta_{R} \mathbf{K}_{u u} .
$$

The Rayleigh damping coefficients $\alpha_{R}$ and $\beta_{R}$ can be confirmed through [4].

\section{Numerical Results}

In this section, the convergence and accuracy of the S-FSDTbased IGA method is verified through some numerical examples. Then, the open-loop control and closed-loop control of piezoelectric functionally graded plates are investigated by using the modified piezoelectric constitutive equation. In the vibration control, the Newmark- $\beta$ method [44] is adopted for researching the transient response of PFGPs, and the parameters $\gamma$ and $\beta$ are set to be 0.5 and 0.25 , respectively.

4.1. Convergence Verification. Let us consider a simply supported PFGP with sizes of $a=b=400 \mathrm{~mm}, h_{f}=5 \mathrm{~mm}$, and $h_{p}=0.1 \mathrm{~mm}$. The functionally graded plate is composed of $\mathrm{ZrO}_{2}$ and $\mathrm{Al}$. The material parameters of metal and ceramic are reported in Table 1 . The piezoelectric layers are PZT-G1195N, and the material properties are $E_{11}=E_{22}=E_{33}=63 \mathrm{GPa}, \quad v_{12}=v_{13}=v_{23}=0.3, \rho=7600 \mathrm{~kg} /$ $\mathrm{m}^{3}, d_{31}=d_{32}=254 \times 10^{-12} \mathrm{~m} / \mathrm{V}$, and $g_{33}=15 \times 10^{-9} \mathrm{~F} / \mathrm{m}$.

Using the cubic NURBS basis functions, Table 2 lists the first six natural frequencies of the plate with different mesh levels. One can see that the results of this work are in good agreement with those in [13]. Besides, the difference between the levels of $16 \times 16$ and $18 \times 18$ can be negligible. Therefore, the mesh of $16 \times 16$ is employed in the following analysis.

\subsection{Comparison Studies}

4.2.1. Piezoelectric Bimorph Beam. As shown in Figure 2, the beam consists of two PVDFs with opposite polarization directions. The sizes of the beam are $100 \mathrm{~mm} \times 5 \mathrm{~mm} \times 1 \mathrm{~mm}$. The material properties are $E_{11}=E_{22}=2.0 \mathrm{GPa}, \quad G_{12}=1.0 \mathrm{GPa}, \quad v_{12}=0$, $e_{31}=e_{32}=0.046 \mathrm{C} / \mathrm{m}^{2}$, and $g_{11}=g_{22}=g_{33}=0.1062 \times 10^{-9}$ $\mathrm{F} / \mathrm{m}$. Figure 3 shows the centerline deflection of the beam under $1 \mathrm{~V}$ voltage. One can see that the results in this work match well with the theory solution presented by Tzou [45].

4.2.2. Static Bending of FGP in Thermal Environment. The length and thickness of a square SSSS $\mathrm{ZrO}_{2} / \mathrm{Al}$ FGP are $200 \mathrm{~mm}$ and $10 \mathrm{~mm}$. Assumed that the plate is subjected to the temperature gradient of $T_{c}=300^{\circ} \mathrm{C}$ and $T_{m}=20^{\circ} \mathrm{C} \cdot q_{0}$ is an increasing transverse distributed load from 0 to $-1 \times 10^{-7} \mathrm{~N} / \mathrm{m}^{2}$. Figure 4 plots the trend of the dimensionless central deflection $\left(\bar{w}=w / h_{f}\right)$ with the parameterized load $\left(\bar{P}=q_{0} a^{4} / E_{m} h_{f}^{4}\right)$. Also based on the IGA, although the S-FSDT has only four variables, it is still as accurate and effective as HSDT [46].

\subsection{Parametric Studies}

4.3.1. Piezoelectric Stress and Dielectric Parameters. Similar to equations (8) and (9), we can also define the temperature-dependent piezoelectric stress parameter $\widehat{e}_{31}$ and dielectric parameter $\widehat{g}_{33}$ as

$$
\begin{aligned}
& \widehat{e}_{31}=e_{31}+\widetilde{e}_{31} \Delta T, \\
& \widehat{g}_{33}=g_{33}+\widetilde{g}_{33} \Delta T,
\end{aligned}
$$

where $e_{31}$ and $g_{33}$ are piezoelectric stress and dielectric constants at temperature $T_{0}=0^{\circ} \mathrm{C}$.

Wang et al. [21] measured the piezoelectric strain constant $\widehat{d}_{31}$ and dielectric constant $\widehat{g}_{33} / \varepsilon_{0}$ of PZT-5A at 
different temperature, where $\varepsilon_{0}=8.85 \times 10^{-12} \mathrm{farad} / \mathrm{m}$. Therefore, PZT-5A is selected as the actuators and sensors in subsequent investigations. Figure 5 plots the experimental data of $\widehat{d}_{31}$ and $\hat{g}_{33} / \varepsilon_{0}$ and their fitted curves. Through the equations of the fitted curves, $\widehat{e}_{31}$ and $\widehat{g}_{33}$ can be expressed as

$$
\begin{aligned}
\hat{e}_{31}= & -34.1599-0.1053 \Delta T, \\
\hat{g}_{33}= & 2.717835 \times 10^{-8}+1.3629 \times 10^{-10} \Delta T \\
& +2.43375 \times 10^{-13} \Delta T^{2}-7.08 \times 10^{-15} \Delta T^{3} \\
& -4.2834 \times 10^{-17} \Delta T^{4}+7.2039 \times 10^{-19} \Delta T^{5} .
\end{aligned}
$$

4.3.2. Temperature Distribution of PFGP. We now study the temperature distribution of a PFGP with sizes of $a=b=400 \mathrm{~mm}, h_{f}=5 \mathrm{~mm}$, and $h_{p}=0.1 \mathrm{~mm}$. The FGP is composed of $\mathrm{ZrO}_{2}$ and $\mathrm{Al}$. The material properties of PZT$5 \mathrm{H}$ are $E=63 \mathrm{Gpa}, v=0.3, k=2.1 \mathrm{~W} / \mathrm{mK}, \alpha=5 \times 10^{-9} /{ }^{\circ} \mathrm{C}$, $\rho=7500 \mathrm{~kg} / \mathrm{m}^{3}$, and $P_{3}=4 \times 10^{-4}\left(\mathrm{C} / \mathrm{m}^{2 \circ} \mathrm{C}\right)$.

Many studies $[12,13]$ of PFGPs ignored the heat conduction of the piezoelectric layers and directly applied thermal loads to the FGPs. Figure 6 shows the temperature distribution along the thickness of FGP under the temperature gradient of $T_{c}=100^{\circ} \mathrm{C}$ and $T_{m}=0^{\circ} \mathrm{C}$. It is seen that the temperature through the thickness shows a linear distribution in the case that the plate is homogeneous. However, the temperature presents a nonlinear distribution and is lower than that in the homogeneous plate when the plate is non-homogeneous. Figure 7 shows the temperature distribution of PFGP under the temperature gradient of $T_{u}=100^{\circ} \mathrm{C}$ and $T_{l}=0^{\circ} \mathrm{C}$. One can find that the temperature distribution of considering the heat conduction of the piezoelectric layers is completely different from that without considering the heat conduction. Besides, the temperature also presents a linear distribution when $n$ is equal to zero. This is because the thermal conductivity of $\mathrm{ZrO}_{2}$ and PZT$5 \mathrm{~A}$ are almost identical.

4.3.3. Static Bending of PFGPs. Figure 8 plots the centerline deflection of the plate subjected to a surface load of $-100 \mathrm{~N} /$ $\mathrm{m}^{2}$. It is seen that the deflection increases with the increase in $n$. This is because the increase in $n$ decreases the stiffness of the plate.

Figure 9 visualizes the centerline deflection under the thermal load $T_{c}=100^{\circ} \mathrm{C}$ and $T_{m}=0^{\circ} \mathrm{C}$. It can be seen that all the deflections are downward, and the deflection of the plate with $n=\infty$ is larger than the deflection with $n=0$. This is because the thermal expansion coefficient of $\mathrm{Al}$ is larger than $\mathrm{ZrO}_{2}$.

Figure 10(a) plots the centerline deflection under thermal load of $T_{u}=100^{\circ} \mathrm{C}$ and $T_{l}=0^{\circ} \mathrm{C}$. The deflections are no longer all downward, and the deflection with $n=0$ is greater than that with $n=\infty$. This is on account of the thickness of the piezoelectric layer is very small, and the deflection is mainly generated by the temperature gradient of FGP. From Figure 7, we can see that the temperature distribution of the FGP with $n=0$ is obviously larger than that of $n=\infty$. Additionally, there is a difference between the deflection that considers the temperature effect of the piezoelectric parameters (in solid line) and the deflection that does not consider the temperature effect (in dash line). Figure 10(b) plots the centerline deflection with $h_{p}=0.5 \mathrm{~mm}$. One can observe that, with the increase in the thickness of the piezoelectric layers, the deformation of the plate is changed and the difference is amplified. Figure 11 shows the centerline deflection under the temperature gradient of $T_{u}=160^{\circ} \mathrm{C}$ and $T_{l}=0^{\circ} \mathrm{C}$. The results indicate that, with the increase in temperature rise, the difference also increases because the modified piezoelectric constitutive method used in this paper is established according to the experimental data of the dielectric and stress parameters in the thermal environment. Certainly, it can help to calculate and simulate the mechanical behavior of smart piezoelectric structures closer to the actual situation.

Next, the open-loop control of PFGPs is studied, in which both two piezoelectric layers act as actuators. Figure 12 shows the centerline deflection of the plate with $n=0.5$ under a mechanical load of $-100 \mathrm{~N} / \mathrm{m}^{2}$ and different voltages. Figure 13 plots the centerline deflection under the temperature gradient of $T_{u}=100^{\circ} \mathrm{C}$ and $T_{l}=0^{\circ} \mathrm{C}$ and different voltages. As expected, the deflection under mechanical and thermal loads can be reduced by increasing the input voltage.

4.3.4. Static Bending Closed-Loop Control. In the analysis of static bending closed-loop control, $G_{d}$ is used to control the static deformation of the plate, and $G_{v}$ is set to be zero. Figures 14 and 15 show the control effect of centerline deflection under the mechanical load of $-100 \mathrm{~N} / \mathrm{m}^{2}$ and temperature gradient of $T_{u}=100^{\circ} \mathrm{C}$ and $T_{l}=0^{\circ} \mathrm{C}$, respectively. We can see that the deflection can be effectively controlled by using the displacement feedback control gain $G_{d}$.

4.3.5. Active Vibration Control of PFGPs. The former CFFF PFGP is employed for investigating the active vibration control. Assumed that the plate suffers an initial transverse surface load of $-100 \mathrm{~N} / \mathrm{m}^{2}$, and then, the load is subsequently removed. Figures 16(a) and 16(b) are the transient responses at the tip of the plate under the temperature rise of $T_{u}=0^{\circ} \mathrm{C}, T_{l}=0^{\circ} \mathrm{C}$ and $T_{u}=100^{\circ} \mathrm{C}, T_{l}=0^{\circ} \mathrm{C}$, respectively. It is seen that, as $G_{v}$ increases, the vibration disappears faster. Besides, because of the existence of thermal load, the vibration amplitude in Figure 16(b) is larger than that in Figure 16(a), and there is still a static offset after the vibration disappears in the thermal environment.

Finally, the active forced vibration control of a SSSS PFGP subjected to four types of distributed transverse loads is investigated. The index $n=1$ and the sizes of plate are $a=b=200 \mathrm{~mm}, h_{f}=10 \mathrm{~mm}$, and $h_{p}=0.5 \mathrm{~mm}$. Four types of loads are defined as follows:

$$
q=q_{0} \sin \left(\frac{\pi x}{a}\right) \sin \left(\frac{\pi y}{b}\right) F(t),
$$

where $q_{0}=10^{5} \mathrm{~N} / \mathrm{m}^{2}$ and 
TABLE 1: Material parameters of FGMs.

\begin{tabular}{lccccc}
\hline Materials & $E(\mathrm{Gpa})$ & $v$ & $k(\mathrm{~W} / \mathrm{mK})$ & $\alpha\left(10^{-6} / \mathrm{K}\right)$ & $\rho\left(\mathrm{kg} / \mathrm{m}^{3}\right)$ \\
\hline $\mathrm{ZrO}_{2}$ & 151 & 0.3 & 2.09 & 10 & 3000 \\
$\mathrm{Al}$ & 70 & 0.3 & 204 & 23 & 2707 \\
\hline
\end{tabular}

TABle 2: The first six natural frequencies $(\mathrm{Hz})$ of the plate with different mesh levels.

\begin{tabular}{lccccc}
\hline \multirow{2}{*}{ Mode } & Method & \multicolumn{5}{c}{$n$} \\
& & 0 & 1 & 5 & $\infty$ \\
\hline \multirow{4}{*}{1} & IGA $(12 \times 12)$ & 205.88 & 177.95 & 167.74 & 150.99 \\
& IGA $(16 \times 16)$ & 205.88 & 177.95 & 167.74 & 150.99 \\
& IGA $(18 \times 18)$ & 205.88 & 177.95 & 167.74 & 150.99 \\
& {$[13]$} & 207.02 & 178.93 & 168.45 & 151.51 \\
\hline \multirow{4}{*}{$2 / 3$} & IGA $(12 \times 12)$ & 514.26 & 444.50 & 418.95 & 377.12 \\
& IGA $(16 \times 16)$ & 514.24 & 444.48 & 418.94 & 377.11 \\
& IGA $(18 \times 18)$ & 514.24 & 444.48 & 418.94 & 377.11 \\
& {$[13]$} & 518.72 & 448.52 & 422.18 & 379.88 \\
\hline \multirow{4}{*}{4} & IGA $(12 \times 12)$ & 822.06 & 710.55 & 669.66 & 602.82 \\
& IGA $(16 \times 16)$ & 822.04 & 710.54 & 669.64 & 602.81 \\
& IGA $(18 \times 18)$ & 822.04 & 710.54 & 669.64 & 602.81 \\
& {$[13]$} & 826.56 & 714.49 & 672.57 & 604.99 \\
\hline \multirow{4}{*}{$5 / 6$} & IGA $(12 \times 12)$ & 1027.20 & 887.86 & 836.70 & 753.22 \\
& IGA $(16 \times 16)$ & 1026.99 & 887.71 & 836.56 & 753.09 \\
& IGA $(18 \times 18)$ & 1026.97 & 887.68 & 836.54 & 753.07 \\
& {$[13]$} & 1038.50 & 898.23 & 845.34 & 760.93 \\
\hline
\end{tabular}

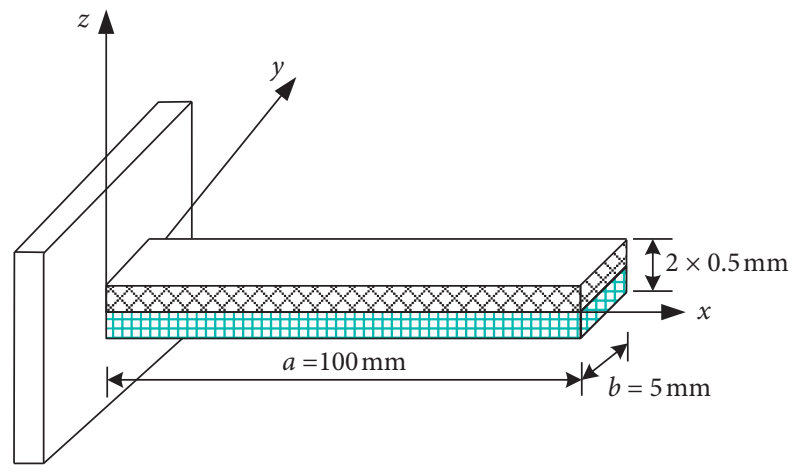

Figure 2: Piezoelectric bimorph beam.

$$
F(t)= \begin{cases}1, & \text { Step load, } \\ 1-t / t_{1} & \text { Triangular load, } \\ \sin \left(\pi t / t_{1}\right) \text { Sinusoidal load, } e^{-\bar{r} t} \text { Explosive load, if } 0 \leq t \leq t_{1}, 0, \text { if } t \geq t_{1}, & \end{cases}
$$

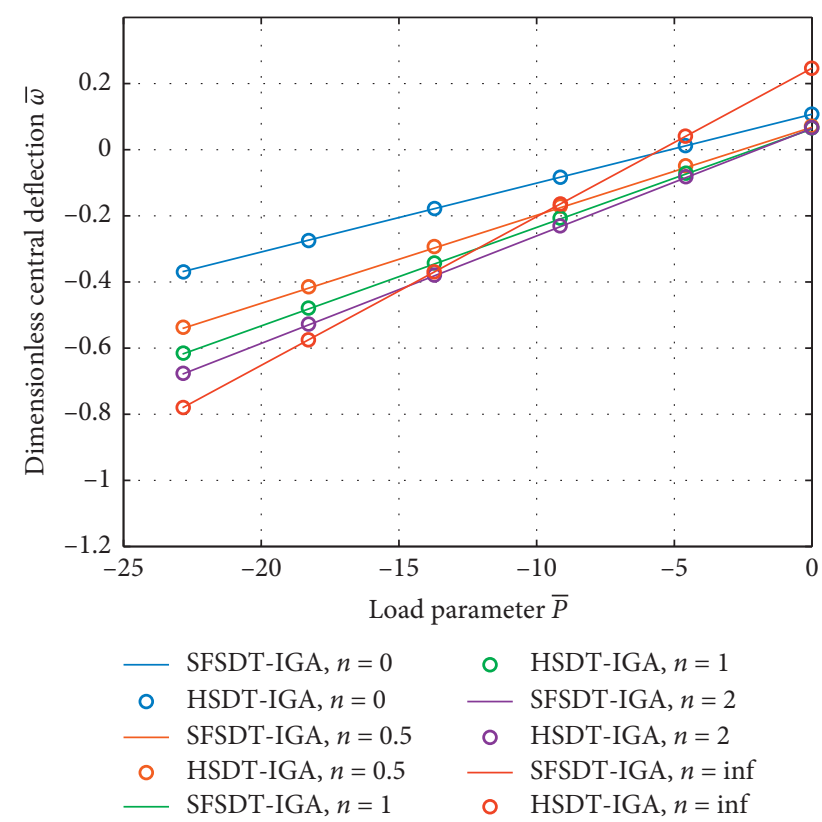

FIgURE 4: Trend of the dimensionless central deflection with the parameterized load.

FIgURe 3: Centerline deflection of the beam under $1 \mathrm{~V}$ voltage.

velocity feedback gain $G_{v}$ can control the vibration of the plate effectively. Because the deflection generated by temperature rise is opposite to that by mechanical loads, the deflection is negative after the vibration disappears in the thermal environment.

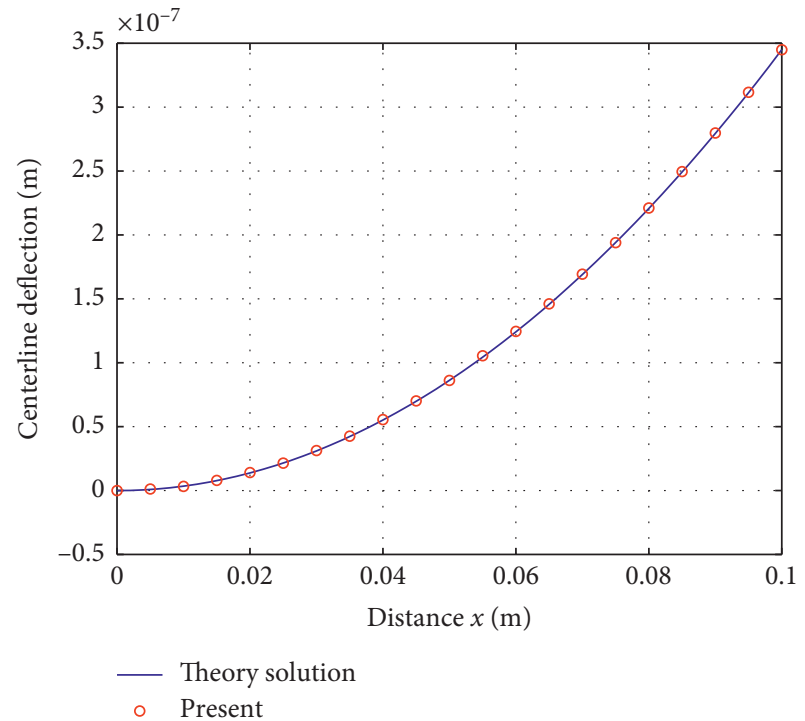

in which $\bar{\gamma}=330 \mathrm{~s}^{-1}$ and $t_{1}=0.003 \mathrm{~s}$.

Figures 17-20 show the central deflection of the plate subjected to step, triangular, sinusoidal, and explosive loads. As expected, both in the forced and free vibration stages, the 


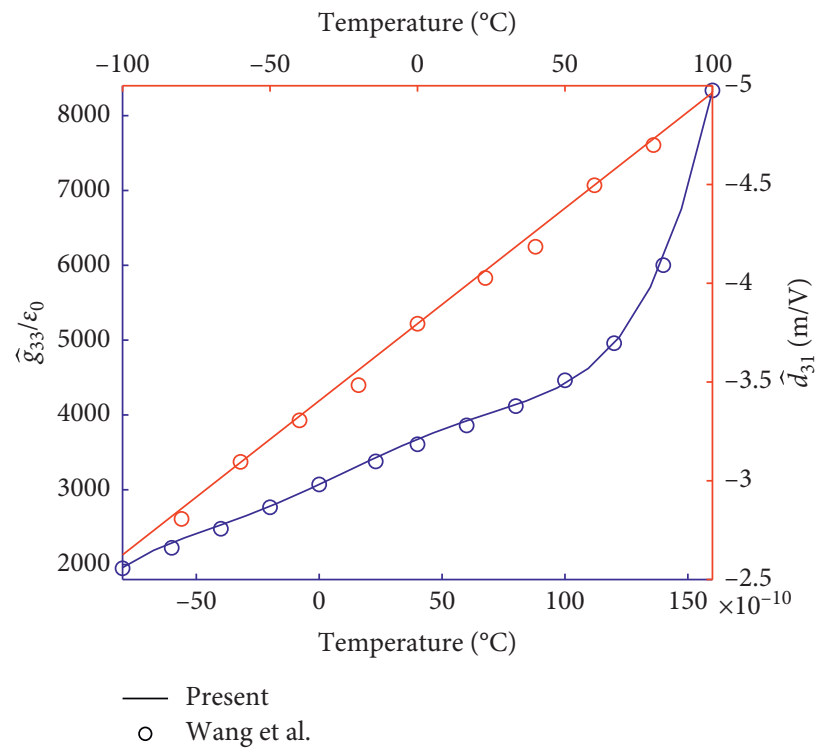

Figure 5: The experimental data of $\widehat{d}_{31}$ and $\hat{g}_{33} / \varepsilon_{0}$ of PZT-5A and their fitted curves.

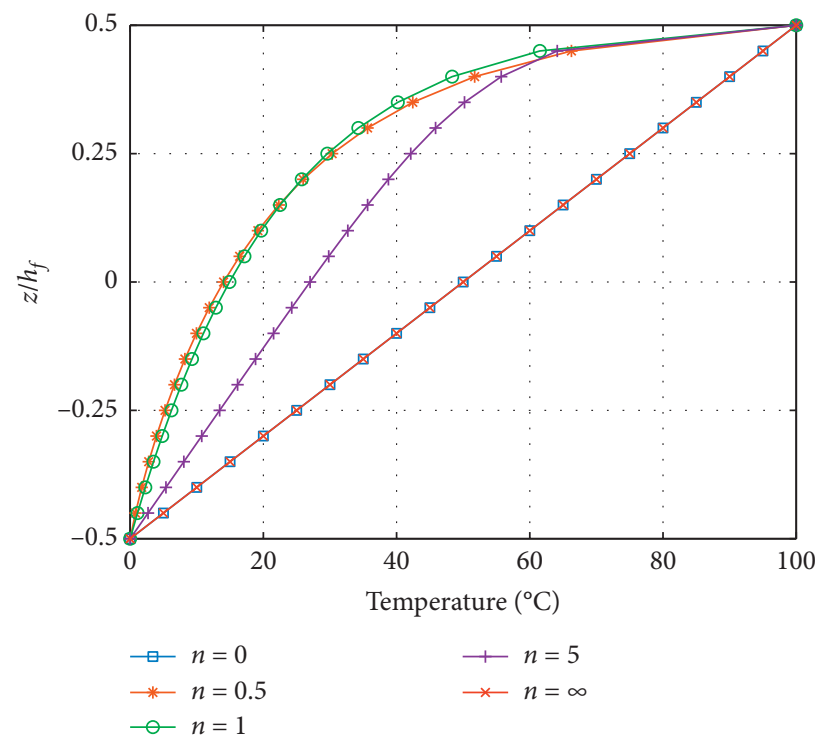

Figure 6: Temperature distribution along the thickness of FGP under a temperature gradient of $T_{c}=100^{\circ} \mathrm{C}$ and $T_{m}=0^{\circ} \mathrm{C}$. 


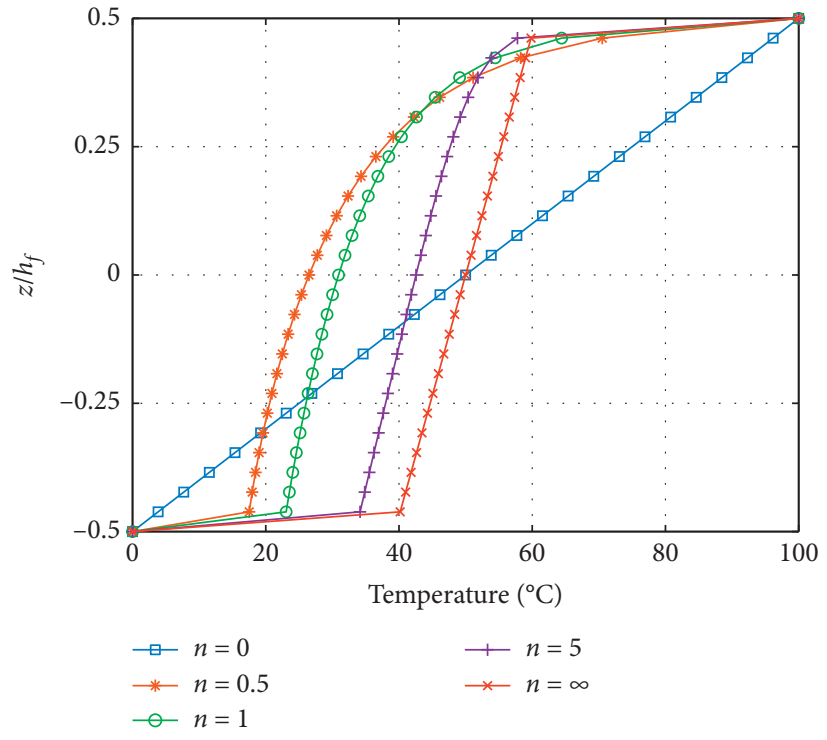

FIgUre 7: Temperature distribution along the thickness of PFGP under a temperature gradient of $T_{u}=100^{\circ} \mathrm{C}$ and $T_{l}=0^{\circ} \mathrm{C}$.

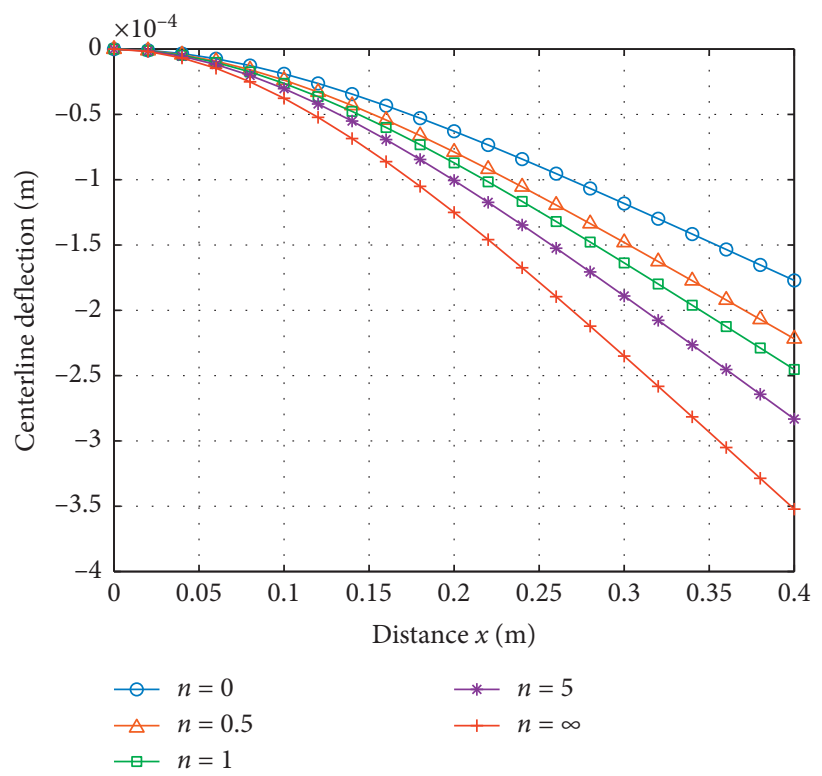

FIGURE 8: Centerline deflection under mechanical load. 


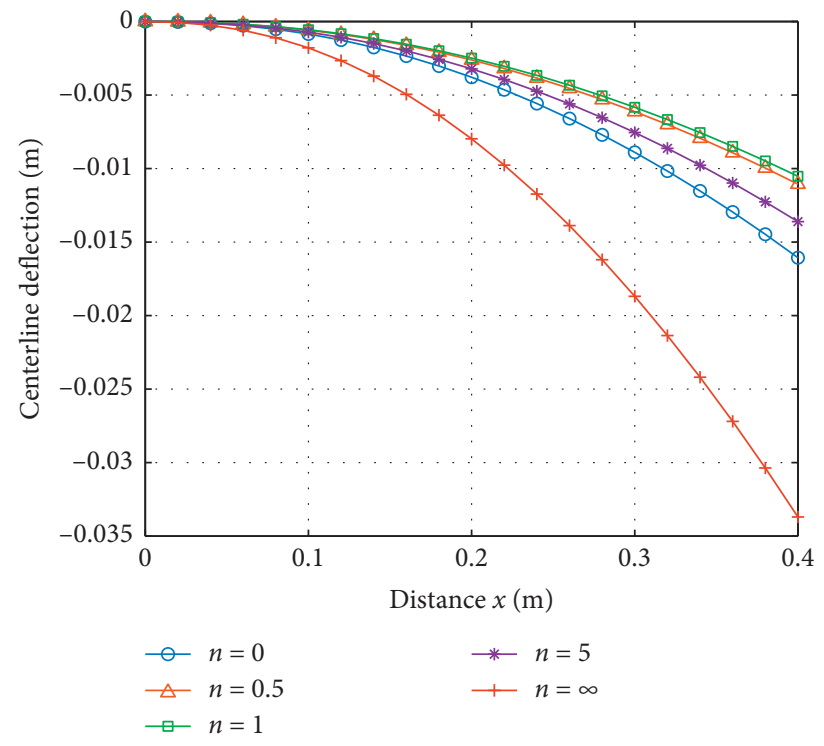

Figure 9: Centerline deflection under the thermal load $T_{c}=100^{\circ} \mathrm{C}$ and $T_{m}=0^{\circ} \mathrm{C}$.

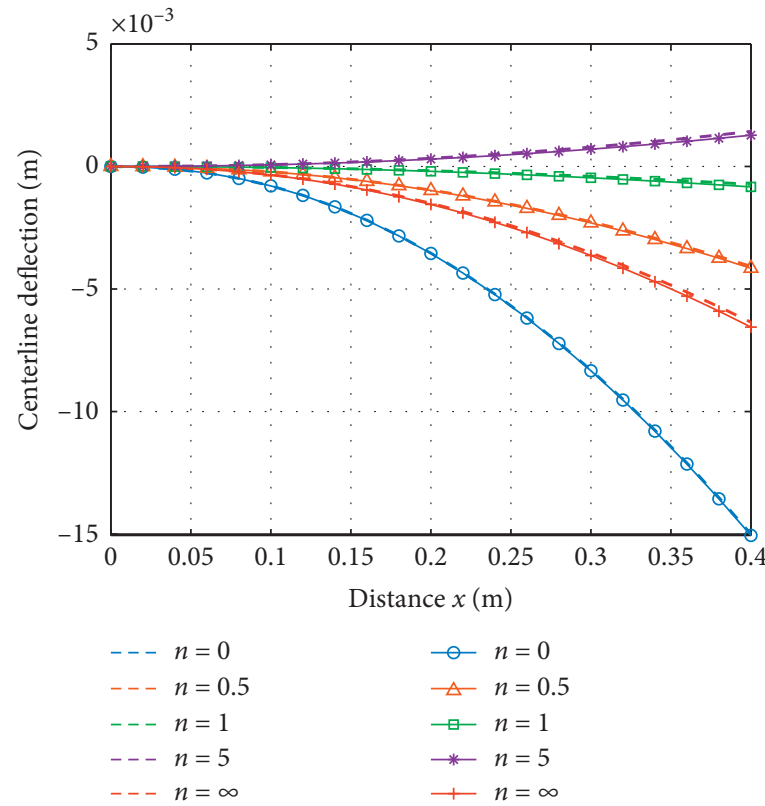

(a)

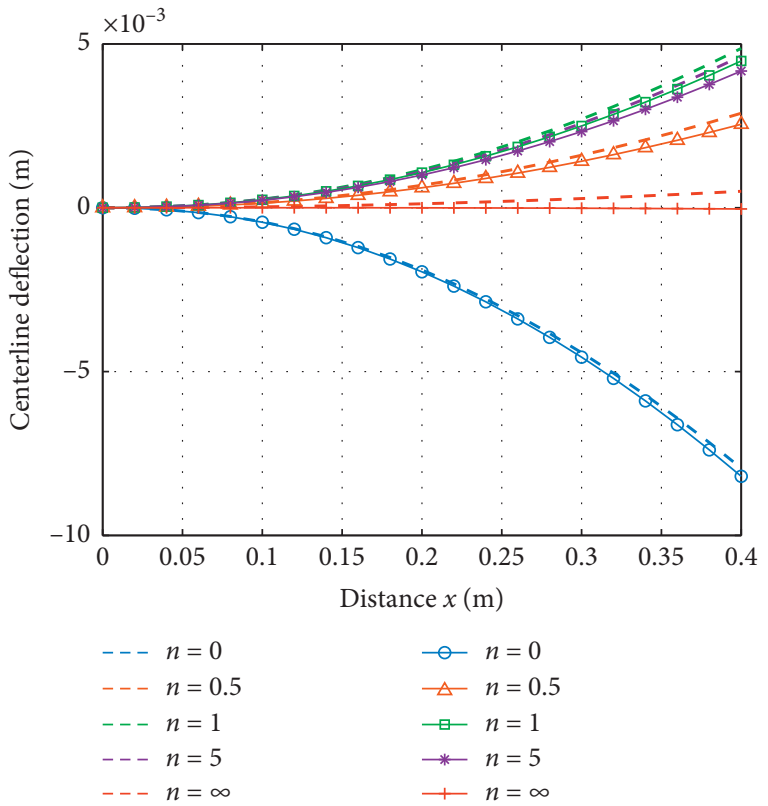

(b)

Figure 10: Centerline deflection with $h_{p}=0.1$ and $0.5 \mathrm{~mm}$ under the thermal load $T_{u}=100^{\circ} \mathrm{C}$ and $T_{l}=0^{\circ} \mathrm{C}:(\mathrm{a}) h_{p}=0.1 \mathrm{~mm}$; (b) $h_{p}=0.5 \mathrm{~mm}$. 


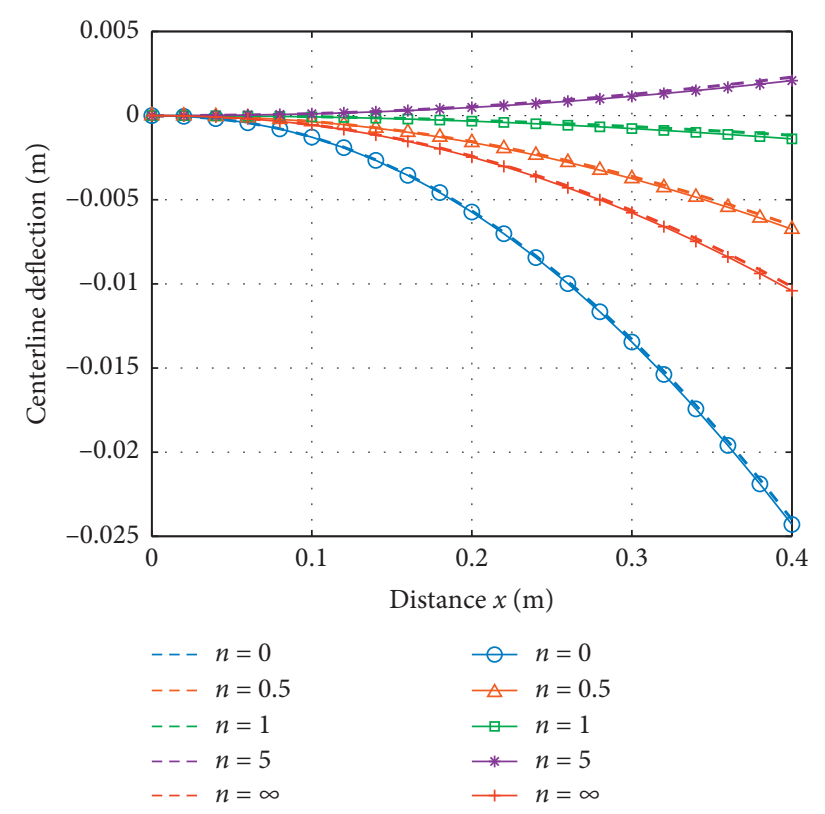

(a)

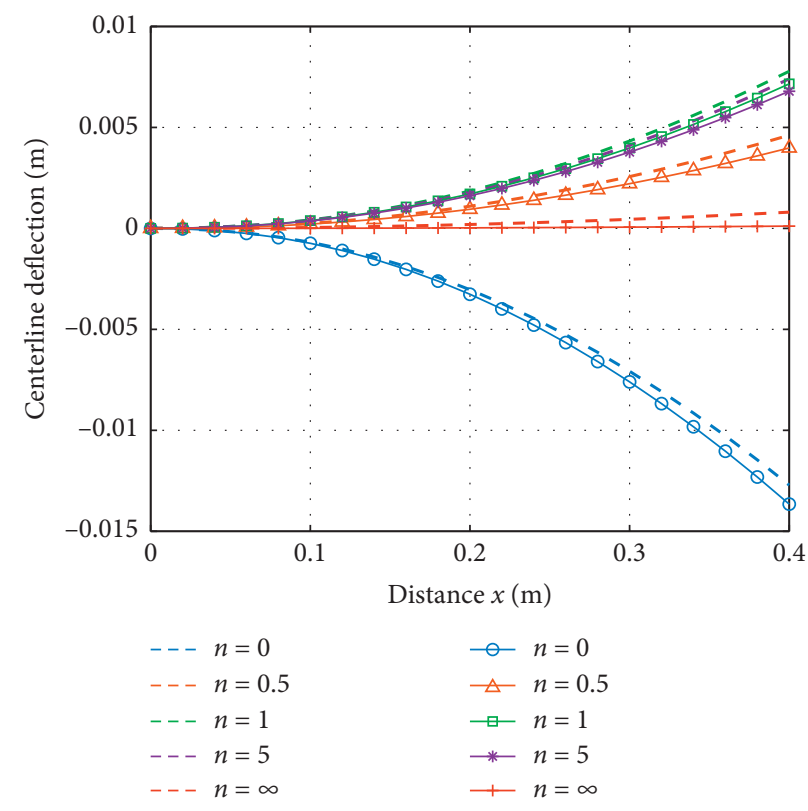

(b)

Figure 11: Centerline deflection with $h_{p}=0.1$ and $0.5 \mathrm{~mm}$ under the thermal load $T_{u}=160^{\circ} \mathrm{C}$ and $T_{l}=0^{\circ} \mathrm{C}:(\mathrm{a}) h_{p}=0.1 \mathrm{~mm}$; (b) $h_{p}=0.5 \mathrm{~mm}$.

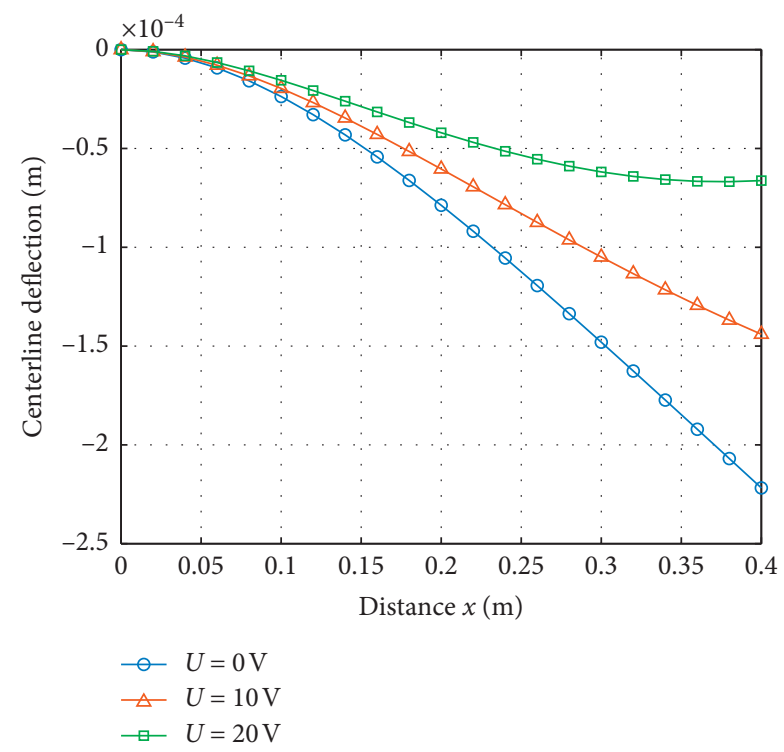

FIGURE 12: Centerline deflection under mechanical load and different voltages. 


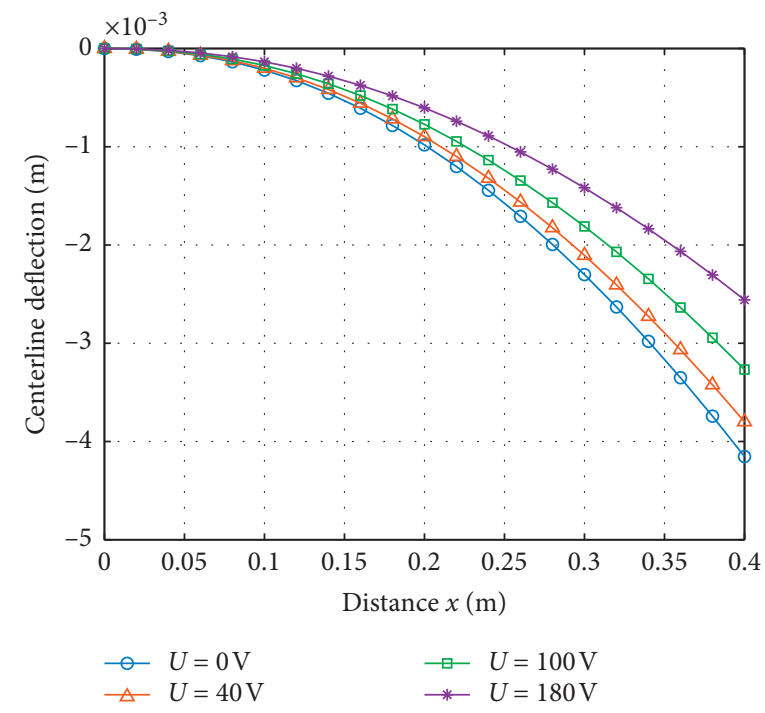

Figure 13: Centerline deflection under thermoelectric load.

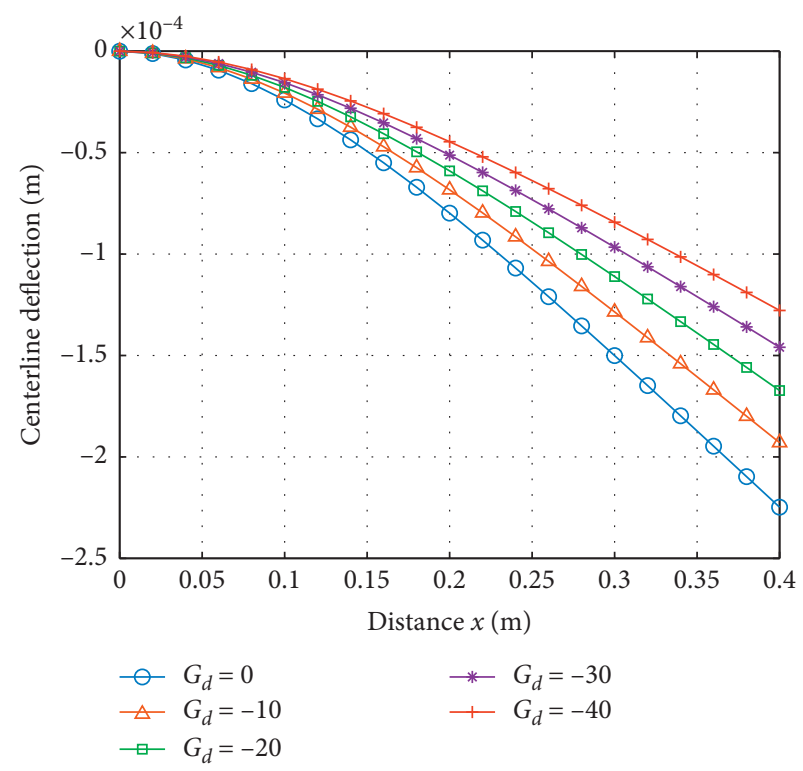

(a)

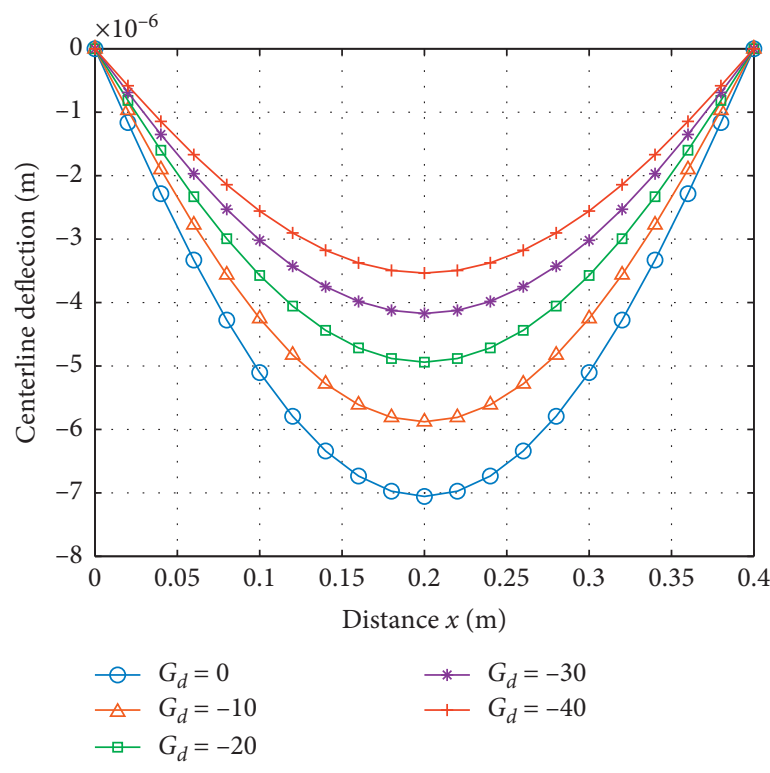

(b)

FIGURE 14: Control effect of centerline deflection under mechanical load: (a) CFFF plate; (b) SSSS plate. 

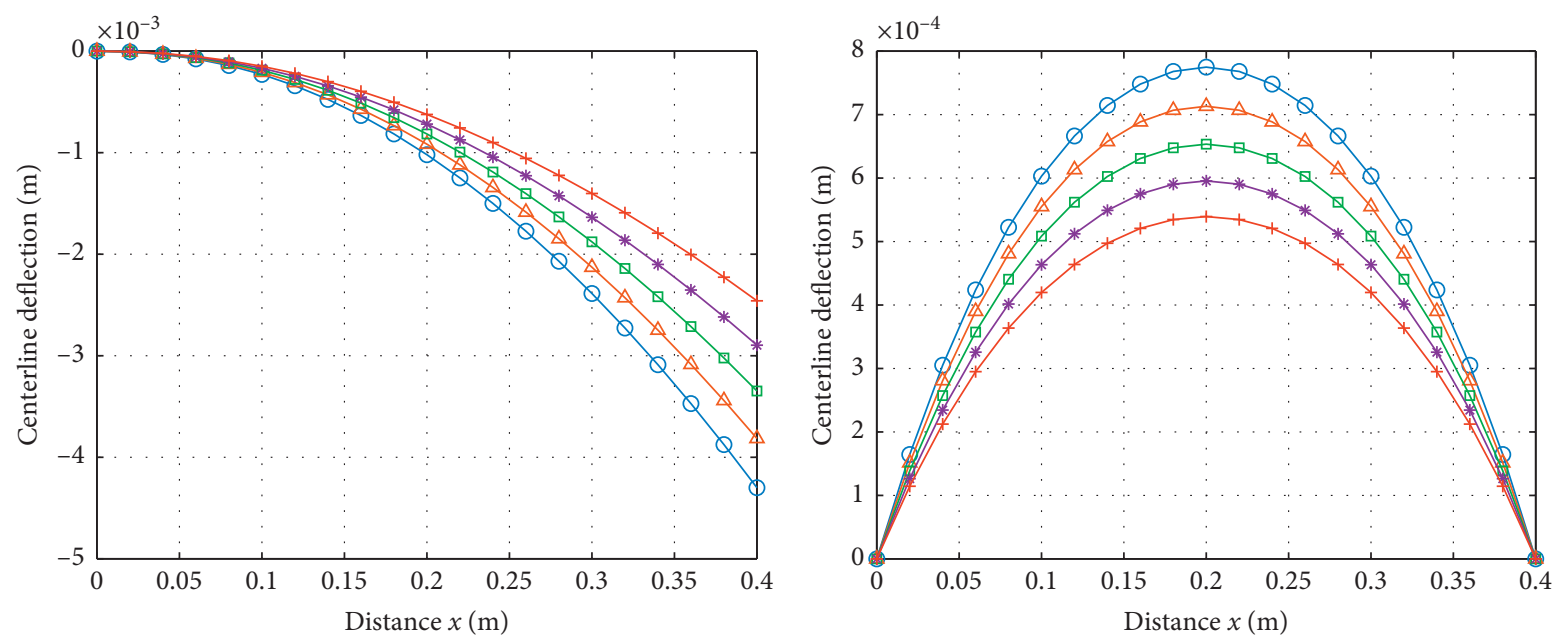

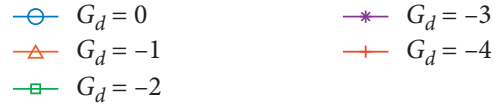

(a)
$\bigcirc G_{d}=0$
$\triangle G_{d}=-1$
$\neg-G_{d}=-2$

(b)

FIGURE 15: Control effect of centerline deflection under thermal load: (a) CFFF plate; (b) SSSS plate.

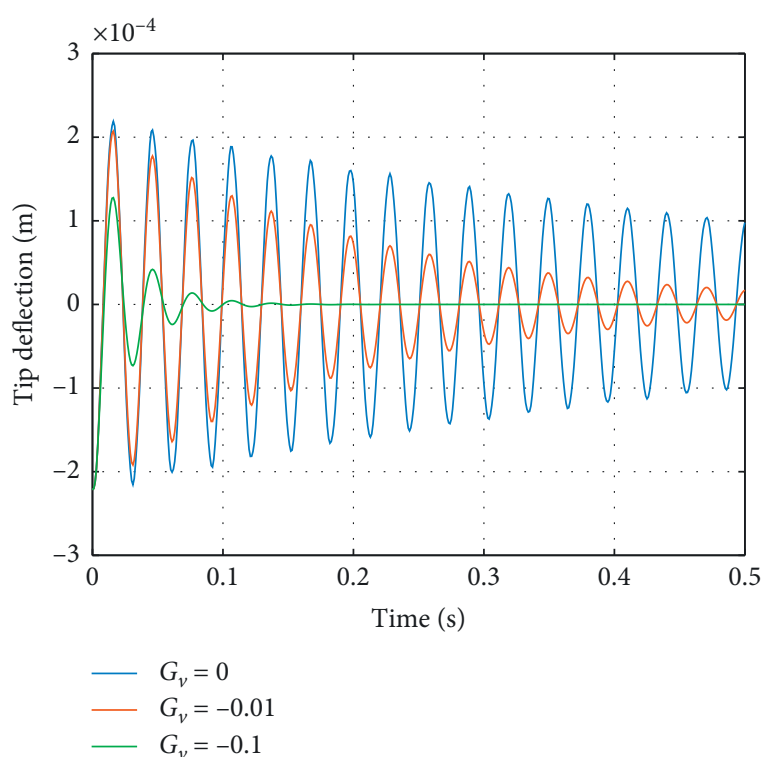

(a)

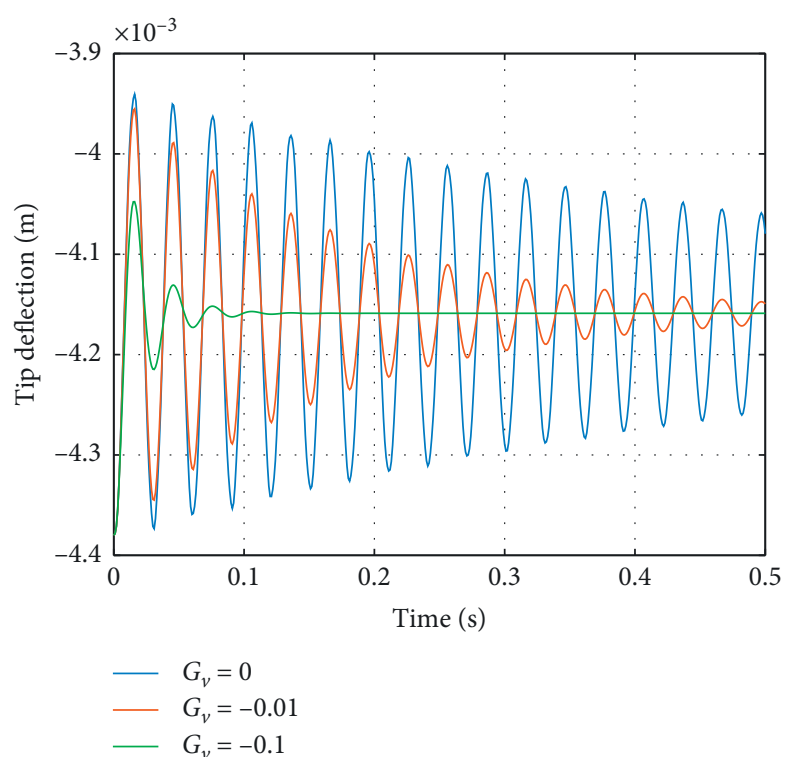

(b)

Figure 16: Transient responses at the tip of the plate: (a) $T_{u}=0^{\circ} \mathrm{C}, T_{l}=0$; (b) $T_{u}=100^{\circ} \mathrm{C}, T_{l}=0$. 


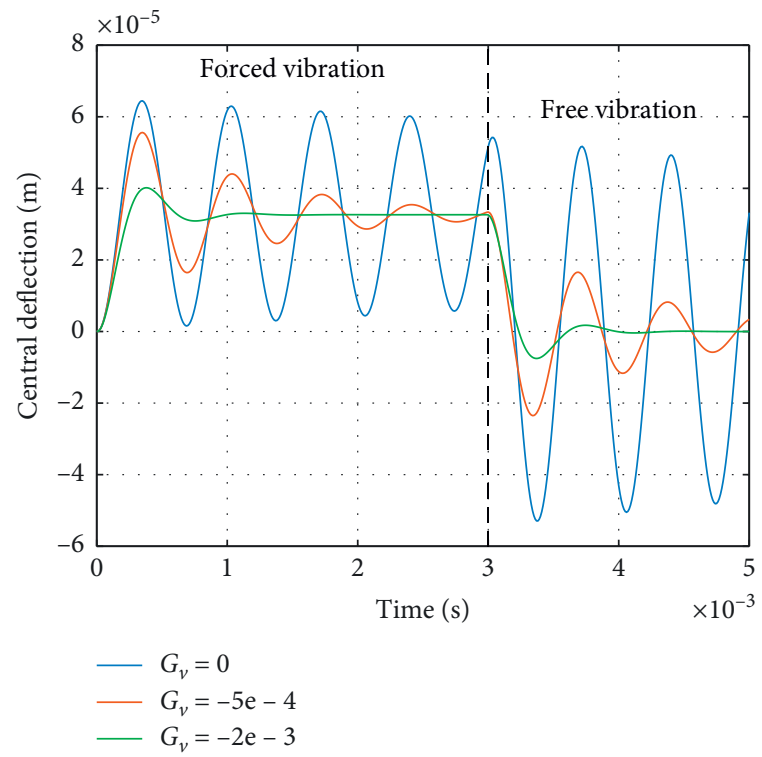

(a)

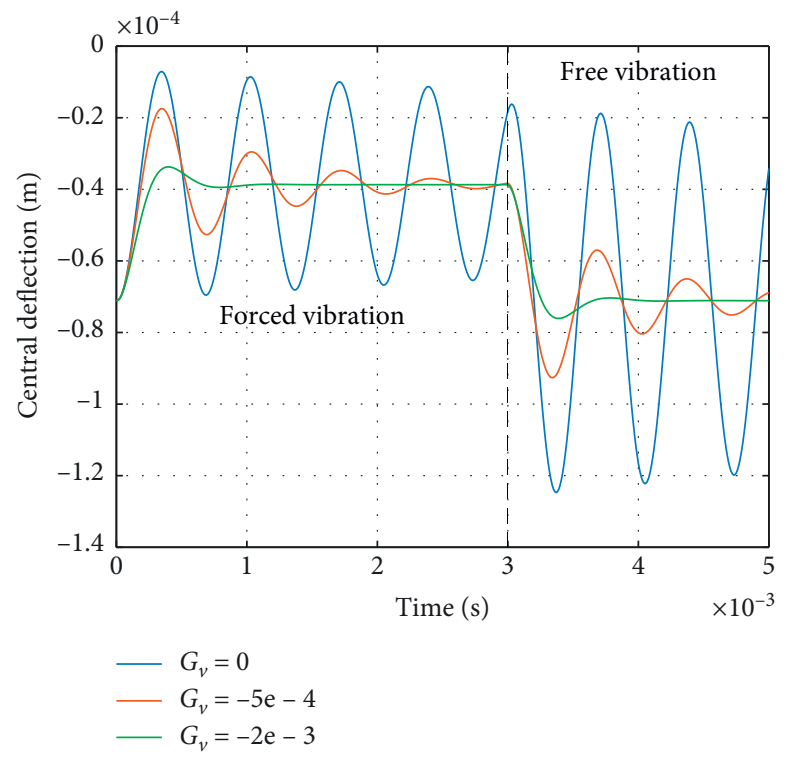

(b)

Figure 17: The central deflection under the step load: (a) $T_{u}=0^{\circ} \mathrm{C}, T_{l}=0$; (b) $T_{u}=100^{\circ} \mathrm{C}, T_{l}=0$.

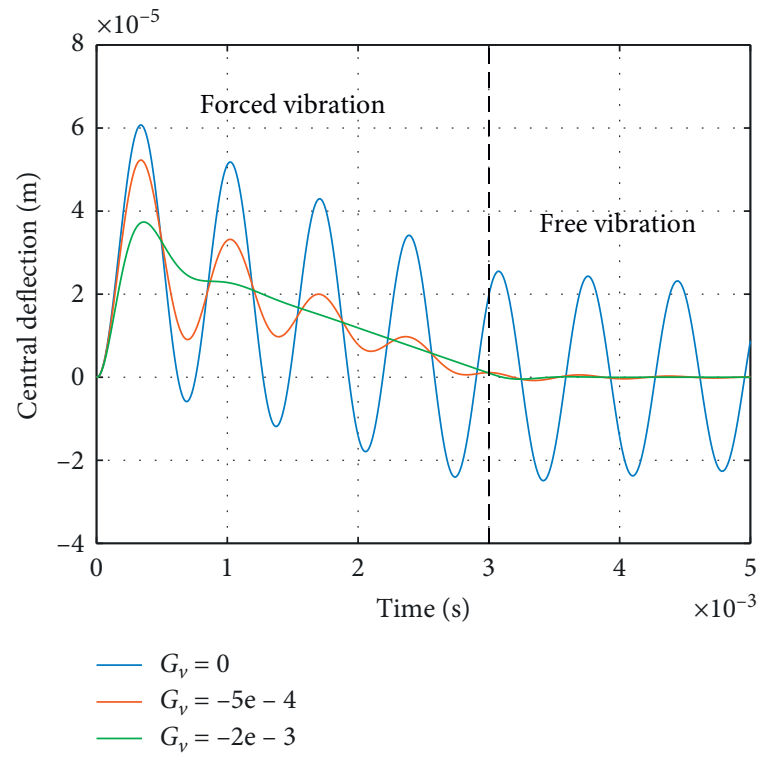

(a)

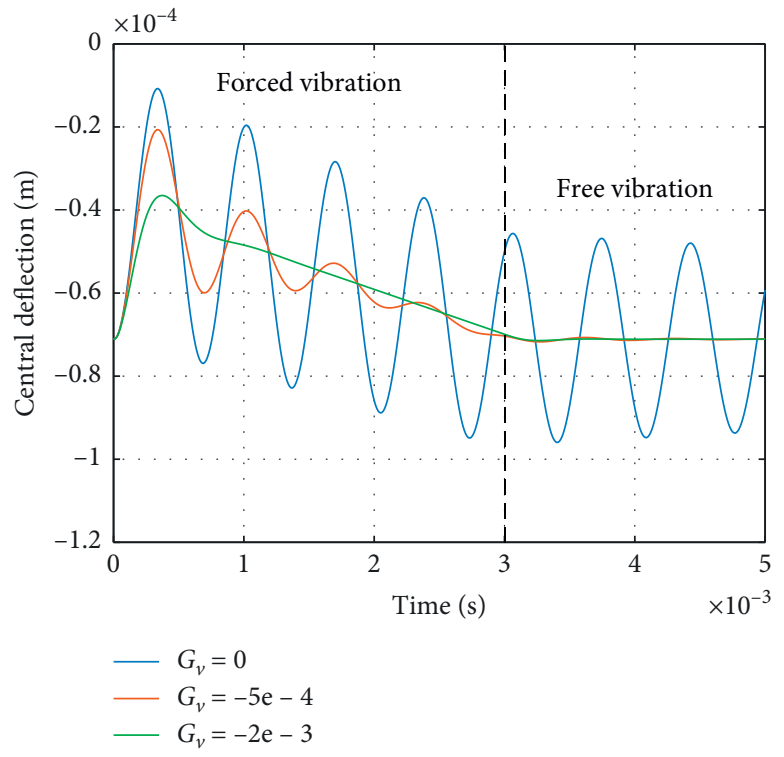

(b)

FIgURE 18: The central deflection under the triangular load: (a) $T_{u}=0^{\circ} \mathrm{C}, T_{l}=0$; (b) $T_{u}=100^{\circ} \mathrm{C}, T_{l}=0$. 


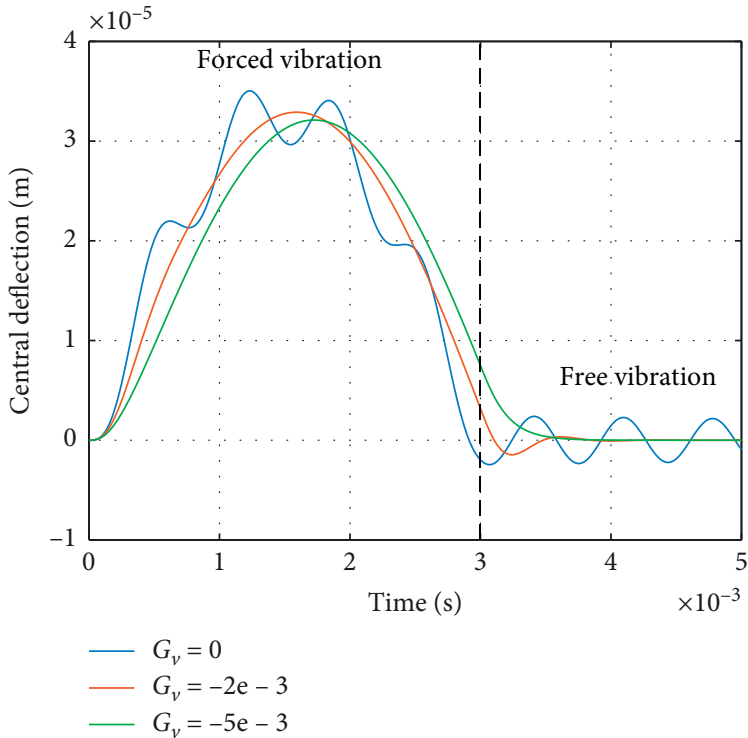

(a)

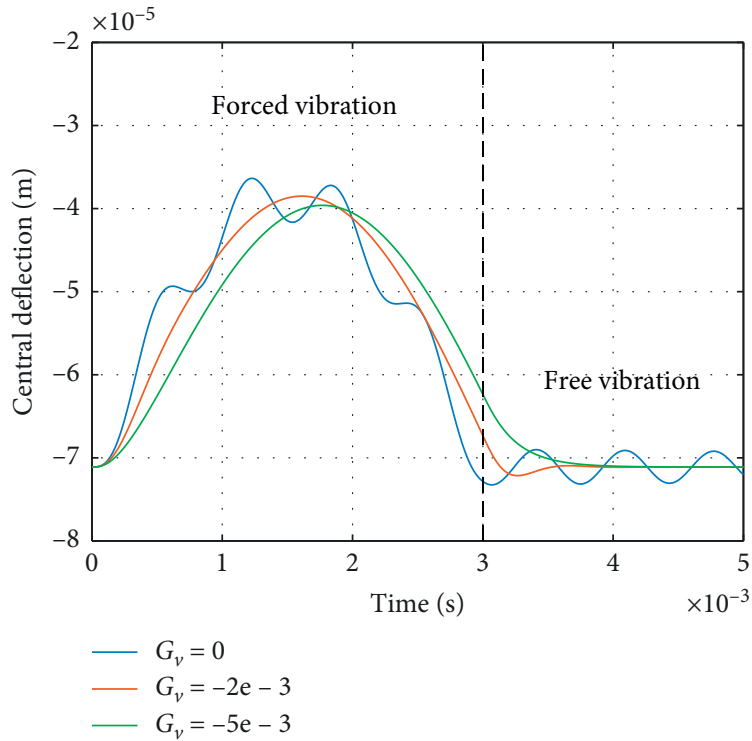

(b)

Figure 19: The central deflection under the sinusoidal load: (a) $T_{u}=0^{\circ} \mathrm{C}, T_{l}=0$; (b) $T_{u}=100^{\circ} \mathrm{C}, T_{l}=0$.

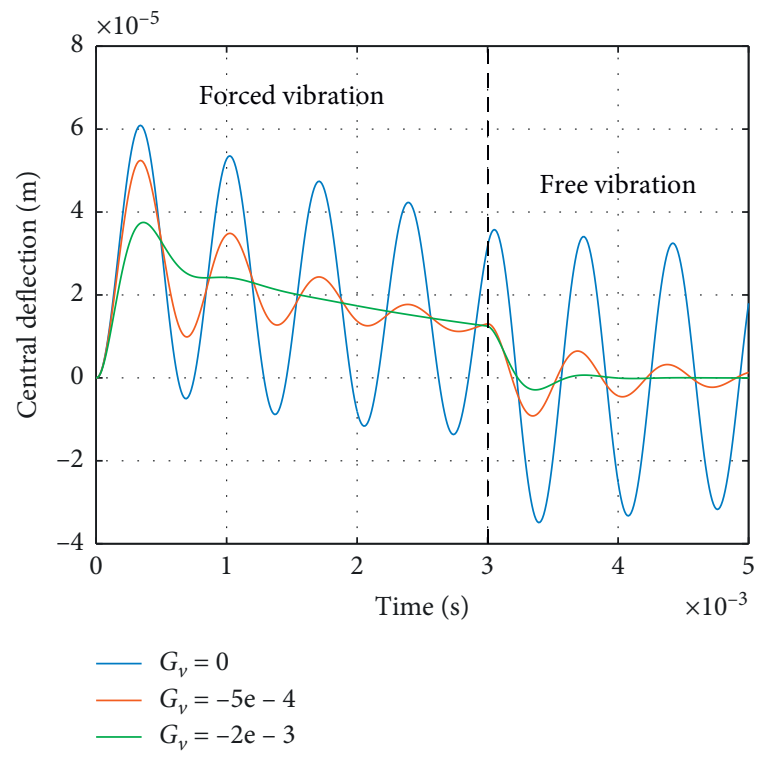

(a)

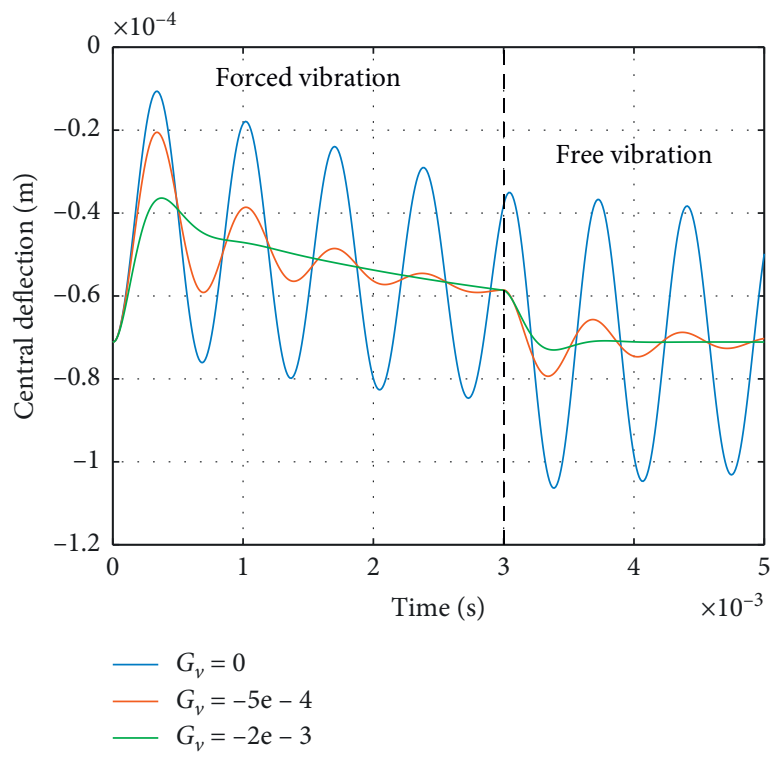

(b)

Figure 20: The central deflection under the explosive load: (a) $T_{u}=0^{\circ} \mathrm{C}, T_{l}=0$; (b) $T_{u}=100^{\circ} \mathrm{C}, T_{l}=0$.

\section{Conclusion}

In this work, we employed a modified piezoelectric constitutive equation with consideration of the temperature effect of dielectric and piezoelectric strain parameters to replace the traditional linear piezoelectric constitutive equation for ensuring the investigation of smart piezoelectric structure in the thermal environment closer to the actual situation. In the selection of numerical methods, an isogeometric analysis (IGA) method combined with a simple first-order shear deformation theory (S-FSDT) was used.
From some numerical examples, some meaningful conclusions can be obtained:

(1) The temperature distribution of considering the heat conduction of piezoelectric layers is completely different from that without considering.

(2) In thermal bending analysis of PFGPs, there is a difference between the results using the modified piezoelectric constitutive equation and those using the traditional linear piezoelectric constitutive equation. And this difference increases with the 
increase in temperature and thickness of piezoelectric layers.

(3) The static deformation of the plates can be controlled according to the requirements by adjusting the control gain $G_{d}$.

(4) The free and forced vibration of the plates can be controlled effectively by using the velocity feedback control gain $G_{v}$. When the plates are subjected to the thermal load, there is a static offset after the vibration disappears.

(5) On the premise of ensuring the working performance of smart piezoelectric structures, to maintain the stability of piezoelectric structure in the thermal environment, the material whose piezoelectric parameters are not sensitive to temperature should be selected as far as possible.

Although the study in this paper has certain reference significance for the engineering application of smart piezoelectric structures, the NURBS-based IGA method still has some shortcomings [47], for instance, the waste of control points caused by refinement. Fortunately, these drawbacks can be avoided by using the rational splines over hierarchical T-meshes (RHT-splines) [31] and polynomial splines over hierarchical T-meshes (PHT-splines) [48]. Thus, introducing these splines techniques into the present formulation would be an interesting work for our future studies.

\section{Data Availability}

The data used to support the findings of this study are included within the article.

\section{Conflicts of Interest}

The authors declare that there are no conflicts of interest regarding the publication of this paper.

\section{Acknowledgments}

This work was supported by the Anhui Science and Technology Major Project (Grant no. 201903a05020029), the University Synergy Innovation Program of Anhui Province (Grant no. GXXT-2019-048), the Open Project of Anhui Province Key Laboratory of Special and Heavy Load Robot (Grant no. TZJQR006-2021), and the Key Program of Natural Science Research of Higher Education in Anhui Province, China (Grant no. KJ2019A0091).

\section{References}

[1] W. Zhang, J. H. Yang, Y. F. Zhang, and S. W. Yang, "Nonlinear transverse vibrations of angle-ply laminated composite piezoelectric cantilever plate with four-modes subjected to inplane and out-of-plane excitations," Engineering Structures, vol. 198, 2019.

[2] A. Menasria, K. Abdelhakim, A. A. Bousahla et al., "A fourunknown refined plate theory for dynamic analysis of FGsandwich plates under various boundary conditions," Steel and Composite Structures, vol. 36, pp. 355-367, 2020.
[3] X. Q. He, T. Y. Ng, S. Sivashanker, and K. M. Liew, "Active control of FGM plates with integrated piezoelectric sensors and actuators," International Journal of Solids and Structures, vol. 38, no. 9, pp. 1641-1655, 2001.

[4] K. Nguyen-Quang, H. Dang-Trung, V. Ho-Huu, H. LuongVan, and T. Nguyen-Thoi, "Analysis and control of FGM plates integrated with piezoelectric sensors and actuators using cell-based smoothed discrete shear gap method (CSDSG3)," Composite Structures, vol. 165, pp. 115-129, 2017.

[5] K. Nguyen-Quang, T. Vo-Duy, H. Dang-Trung, and T. Nguyen-Thoi, "An isogeometric approach for dynamic response of laminated FG-CNT reinforced composite plates integrated with piezoelectric layers," Computer Methods in Applied Mechanics and Engineering, vol. 332, pp. 25-46, 2018.

[6] J. Belinha, A. L. Araújo, L. M. J. S. Dinis, and R. M. Natal Jorge, "The analysis of laminated plates using distinct advanced discretization meshless techniques," Composite Structures, vol. 143, pp. 165-179, 2016.

[7] B. A. Selim, Z. Liu, and K. M. Liew, "Active vibration control of functionally graded graphene nanoplatelets reinforced composite plates integrated with piezoelectric layers," ThinWalled Structures, vol. 145, 2019.

[8] A. Boussoula, B. Boucham, M. Bourada, F. Bourada et al., "A simple nth-order shear deformation theory for thermomechanical bending analysis of different configurations of FG sandwich plates," Smart Structures and Systems, vol. 25, pp. 197-218, 2020.

[9] S. Refrafi, A. A Bousahla, A. Bourada et al., "Effects of hygrothermo-mechanical conditions on the buckling of FG sandwich plates resting on elastic foundations," Computers and Concrete, vol. 25, pp. 311-325, 2020.

[10] J. Yang, S. Kitipornchai, and K. M. Liew, "Large amplitude vibration of thermo-electro-mechanically stressed FGM laminated plates," Computer Methods in Applied Mechanics and Engineering, vol. 192, no. 35-36, pp. 3861-3885, 2003.

[11] J. Yang, S. Kitipornchai, and K. M. Liew, "Non-linear analysis of the thermo-electro-mechanical behaviour of shear deformable FGM plates with piezoelectric actuators," International Journal for Numerical Methods in Engineering, vol. 59, no. 12, pp. 1605-1632, 2004.

[12] K. M. Liew, X. Q. He, T. Y. Ng, and S. Sivashanker, "Active control of FGM plates subjected to a temperature gradient: modelling via finite element method based on FSDT," International Journal for Numerical Methods in Engineering, vol. 52, no. 11, pp. 1253-1271, 2001.

[13] K. Y. Dai, G. R. Liu, X. Han, and K. M. Lim, “Thermomechanical analysis of functionally graded material (FGM) plates using element-free Galerkin method," Computers \& Structures, vol. 83, no. 17-18, pp. 1487-1502, 2005.

[14] X. L. Huang and H. S. Shen, "Vibration and dynamic response of functionally graded plates with piezoelectric actuators in thermal environments," Journal of Sound and Vibration, vol. 289, pp. 25-53, 2005.

[15] X.-K. Xia and H.-S. Shen, "Nonlinear vibration and dynamic response of fgm plates with piezoelectric fiber reinforced composite actuators," Composite Structures, vol. 90, no. 2, pp. 254-262, 2009.

[16] V. Fakhari, A. Ohadi, and P. Yousefian, "Nonlinear free and forced vibration behavior of functionally graded plate with piezoelectric layers in thermal environment," Composite Structures, vol. 93, no. 9, pp. 2310-2321, 2011.

[17] V. Fakhari and A. Ohadi, "Nonlinear vibration control of functionally graded plate with piezoelectric layers in thermal 
environment," Journal of Vibration and Control, vol. 17, no. 3 , pp. 449-469, 2009.

[18] P. Phung-Van, L. V. Tran, A. J. M. Ferreira et al., "Nonlinear transient isogeometric analysis of smart piezoelectric functionally graded material plates based on generalized shear deformation theory under thermo-electro-mechanical loads," Nonlinear Dynamics, vol. 87, no. 2, pp. 1-16, 2016.

[19] Y. Kiani, "Isogeometric large amplitude free vibration of graphene reinforced laminated plates in thermal environment using NURBS formulation," Computer Methods in Applied Mechanics and Engineering, vol. 332, pp. 86-101, 2018.

[20] H. S. Shen, "Nonlinear thermal bending response of FGM plates due to heat conduction," Composites Part. B: Engineering, vol. 38, no. 2, pp. 201-215, 2006.

[21] D. Wang, Y. Fotinich, and G. P. Carman, "Influence of temperature on the electromechanical and fatigue behavior of piezoelectric ceramics," Journal of Applied Physics, vol. 83, no. 10, pp. 5342-5350, 1998.

[22] S. Alimirzaei, M. Mohammadimehr, and A. Tounsi, "Nonlinear analysis of viscoelastic micro-composite beam with geometrical imperfection using FEM: MSGT electro-magneto-elastic bending, buckling and vibration solutions," Structural Engineering and Mechanics, vol. 71, no. 5, pp. 485-502, 2019.

[23] H. Hirane, M. O. Belarbi, M. S. A. Houari et al., "On the layerwise finite element formulation for static and free vibration analysis of functionally graded sandwich plates," Engineering with Computers, vol. 3, 2021.

[24] S. Li, L. Huang, L. Jiang, and R. Qin, "A bidirectional B-spline finite point method for the analysis of piezoelectric laminated composite plates and its application in material parameter identification," Composite Structures, vol. 107, pp. 346-362, 2014.

[25] T. Liu, C. Li, C. Wang et al., "A simple-FSDT-based isogeometric method for piezoelectric functionally graded plates," Mathematics, vol. 8, no. 12, 2020.

[26] M. S. Kiani and M. R. Eslam, "Dynamic analysis and active control of smart doubly curved FGM panels," Composite Structures, vol. 102, pp. 205-216, 2013.

[27] M. Mirzaei and Y. Kiani, "Isogeometric thermal buckling analysis of temperature dependent FG graphene reinforced laminated plates using NURBS formulation," Composite Structures, vol. 180, pp. 606-616, 2017.

[28] Y. Kiani, "NURBS-based isogeometric thermal postbuckling analysis of temperature dependent graphene reinforced composite laminated plates," Thin-Walled Structures, vol. 125, pp. 211-219, 2018.

[29] N. Nguyen-Thanh, N. Valizadeh, M. N. Nguyen et al., "An extended isogeometric thin shell analysis based on KirchhoffLove theory," Computer Methods in Applied Mechanics and Engineering, vol. 284, pp. 265-291, 2015.

[30] H. Ghasemi, H. S. Park, and T. Rabczuk, "A level-set based IGA formulation for topology optimization of flexoelectric materials," Computer Methods in Applied Mechanics and Engineering, vol. 313, pp. 239-258, 2017.

[31] N. Nguyen-Thanh, K. Zhou, X. Zhuang et al., "Isogeometric analysis of large-deformation thin shells using RHT-splines for multiple-patch coupling," Computer Methods in Applied Mechanics and Engineering, vol. 316, pp. 1157-1178, 2017.

[32] N. Bendenia, M. Zidour, A. A. Bousahla et al., "Deflections, stresses and free vibration studies of FG-CNT reinforced sandwich plates resting on Pasternak elastic foundation," Computers and Concrete, vol. 26, no. 3, pp. 213-226, 2020.

[33] A. Bakora, F. Bourada, A. A. Bousahla et al., "Buckling analysis of functionally graded plates using HSDT in conjuction with the stress function method," Computers and Concrete, vol. 27, no. 1, 2021.

[34] B. Akgöz and Ö. Civalek, "A microstructure-dependent sinusoidal plate model based on the strain gradient elasticity theory," Acta Mechanica, vol. 226, no. 7, pp. 2277-2294, 2015.

[35] T. T. Yu, S. Yin, T. Q. Bui et al., "A simple FSDT-based isogeometric analysis for geometrically nonlinear analysis of functionally graded plates," Finite Elements in Analysis and Design, vol. 96, pp. 1-10, 2014.

[36] W. Tian, T. Zhao T, and Z. C. Yang, "Nonlinear electro-thermomechanical dynamic behaviors of a supersonic functionally graded piezoelectric plate with general boundary conditions," Composite Structures, vol. 261, Article ID 113326, 2020.

[37] A. Lal, N. L. Shegokar, and B. N. Singh, "Finite element based nonlinear dynamic response of elastically supported piezoelectric functionally graded beam subjected to moving load in thermal environment with random system properties," $A p$ plied Mathematical Modelling, vol. 44, pp. 274-295, 2017.

[38] N. V. Nguyen, L. B. Nguyen, H. Nguyen-Xuan et al., "Analysis and active control of geometrically nonlinear responses of smart FG porous plates with graphene nanoplatelets reinforcement based on Bézier extraction of NURBS," International Journal of Mechanical Sciences, vol. 180, 2020.

[39] M. M. Al-Zahran, A. Rouabhia, C. Abdelbaki et al., "Physical stability response of a SLGS resting on viscoelastic medium using nonlocal integral first order theory," Steel and Composite Structures, vol. 37, no. 6, pp. 695-709, 2020.

[40] A. A. Bousahla, F. Bourada, S. R. Mahmoud et al., "Buckling and dynamic behavior of the simply supported CNT-RC beams using an integral-first shear deformation theory," Computers and Concrete, vol. 25, no. 2, pp. 155-166, 2020.

[41] N.-I. Kim and J. Lee, "Geometrically nonlinear isogeometric analysis of functionally graded plates based on first-order shear deformation theory considering physical neutral surface," Composite Structures, vol. 153, pp. 804-814, 2016.

[42] C. Wang, J. M. Koh, T. T. Yu et al., "Material and shape optimization of bi-directional functionally graded plates by GIGA and an improved multi-objective particle swarm optimization algorithm," Computer Methods in Applied Mechanics Engineering, vol. 366, 2020.

[43] N. V. Nguyen, J. Lee, and H. Nguyen-Xuan, "Active vibration control of GPLs-reinforced FG metal foam plates with piezoelectric sensor and actuator layers," Composites Part B: Engineering, vol. 172, pp. 769-784, 2019.

[44] Y. Tang, X. Lv, and T. Yang, "Bi-directional functionally graded beams: asymmetric modes and nonlinear free vibration," Composites Part B: Engineering, vol. 156, pp. 319-331, 2019.

[45] H. Tzou, "Development of a light-weight robot end-effector using polymeric piezoelectric bimorph," in Proceedings of the IEEE. International Conference on Robotics and Automation, Scottsdale, AL, USA, May 1989.

[46] L. V. Tran, P. Phung-Van, J. Lee, M. A. Wahab, and H. Nguyen-Xuan, "Isogeometric analysis for nonlinear thermomechanical stability of functionally graded plates," Composite Structures, vol. 140, pp. 655-667, 2016.

[47] N. Nguyen-Thanh, J. Kiendl, H. Nguyen-Xuan et al., "Rotation free isogeometric thin shell analysis using PHT-splines," Computer Methods in Applied Mechanics and Engineering, vol. 200, no. 47-48, pp. 3410-3424, 2011.

[48] N. Nguyen-Thanh, H. Nguyen-Xuan, S. P. A. Bordas, and T. Rabczuk, "Isogeometric analysis using polynomial splines over hierarchical T-meshes for two-dimensional elastic solids," Computer Methods in Applied Mechanics and Engineering, vol. 200, no. 21-22, pp. 1892-1908, 2011. 